\title{
Study on Electrical Characteristics of Magmatic Rock Intrusions in Metamorphic Rock Formations- Taking the Mupi Tunnel of Jiuzhaigou-Mianyang Highway as an Example
}

\section{Bin Li}

Chengdu University of Technology, State Key Laboratory of Geohazard Prevention and Geoenvironment Protection, Sichuan Chengdu

\section{Chongde Feng}

Sichuan Highway Planning, Survey, Design And Research Institute Ltd囚Sichuan Chengdu

\section{Qiang Cheng}

Sichuan Highway Planning, Survey, Design And Research Institute Ltd囚Sichuan Chengdu Jianhua Yu ( $\nabla$ yujianhua@schdri.com)

Sichuan Highway Planning, Survey, Design And Research Institute Ltd囚Sichuan Chengdu Hu Zhao

Sichuan Highway Planning, Survey, Design And Research Institute Ltd囚Sichuan Chengdu

\section{Xuepei Xiao}

Sichuan Highway Planning, Survey, Design And Research Institute Ltd囚Sichuan Chengdu

\section{Research Article}

Keywords: highway, tunnels, magnetotelluric, survey, engineering geology

Posted Date: April 6th, 2021

DOI: https://doi.org/10.21203/rs.3.rs-384306/v1

License: (c) (i) This work is licensed under a Creative Commons Attribution 4.0 International License. Read Full License 


\title{
Study on electrical characteristics of magmatic rock intrusions in metamorphic rock formations
}

\begin{abstract}
The stratum lithology and geological structure of the highway tunnel in the mountainous areas of western China are complex, and the engineering geological conditions are complicated. When the highway tunnel passes through different lithological strata, its structural design and construction are completely different. Therefore, the design and construction of the supporting tunnel are used in the tunnel survey. The identification of the contact boundary between magmatic rock and metamorphic rock and the grade of surrounding rock is very important. The data processing, forward numerical simulation, 1D, 2D, and 3D inversion of the G8513 Jiuzhaigou-Mianyang Expressway Mupi Tunnel survey by magnetotelluric method reveals the ground level along the design line of the tunnel to the depth of $50 \mathrm{~m}$ depths within the design elevation of the tunnel. Electrical characteristics, focusing on the identification of the contact boundary between magmatic rock and metamorphic rock. This study provides the electrical characteristics of the magmatic rock and metamorphic rock contact boundary of the Mupi Tunnel. It is speculated that the boundary is revealed by the tunnel construction excavation, which verifies the correctness of the geophysical inversion model and provides a more detailed design basis for the tunnel design. It is believed that taking the Mupi tunnel survey as an example, this research can provide detailed geophysical basis for the identification of magmatic rock and metamorphic rock in highway tunnels, as well as the geological survey and design of highway tunnels.
\end{abstract}

Keywords: highway, tunnels, magnetotelluric, survey, engineering geology

\section{Introduction}

Western China is a mountainous region, with complex topographical conditions and geological structures, and poor engineering geological conditions. In order to meet the design requirements, the route inevitably needs to be designed to pass through deep-buried super-long tunnels in the hilly area. Tunnel engineering occupies a large proportion of the highway construction in the western mountainous areas ${ }^{29}$.

If the highway tunnel must pass through different lithological strata, if the structure and foundation form are not properly selected, it is easy to cause collapse and structural instability during construction and later highway operation. Therefore, in the preliminary survey and design process, the stratum lithology should be fully identified and provided More accurate information to avoid subsequent problems.

Geophysical prospecting is one of the important methods used in various stages of tunnel engineering geological survey ${ }^{7-}$

22 . Engineering geological surveying, drilling, geophysical prospecting and many other methods are used to comprehensively evaluate engineering geology in order to provide as detailed basic information as possible for the design and construction of highway tunnels. Magnetotelluric method is widely used in highway tunnel surveys because of its large survey depth and high efficiency $^{1-7}$.

In the past few years, Yu Nian has carried out the application and research of magnetotelluric sounding in the engineering geological survey of railway tunnels ${ }^{15}$. Zhao Guoze ${ }^{22}$, Yang Wencai ${ }^{23}$ and others ${ }^{24-25}$ have studied the magnetotelluric method to detect the deep electric structure of the crust and the interpretation of magnetotelluric data under complex structural conditions. Booker and Parker has written and published many papers in various aspects such as processing, inversion, interpretation, respectively studying the methods and applications of magnetotelluric from acquisition to geological interpretation, and has obtained many research results ${ }^{13,18,20}$.

We launched the investigation and application research of magnetotelluric sounding method in highway tunnels. The application research of the electrical characteristics of magmatic rock and metamorphic rock contact boundary in the investigation of highway tunnels.

Taking the Mupi Tunnel of Jiuzhaigou-Mianyang Highway as an example, the study of the electrical characteristics of the magmatic rock intrusions in the metamorphic rock formations of highway tunnels by magnetotelluric method is carried out, revealing the various layers within a depth of $50 \mathrm{~m}$ within the design elevation of the Mupi tunnel's electrical characteristics of the structure, focusing on the forward numerical simulation, inversion calculation and geological interpretation of the electrical characteristics of the tunnel located in the metamorphic rock containing magmatic rock intrusions, and the technical route of the verification results revealed by the tunnel construction excavation to solve the scientific problems and engineering 
technical solutions of the validity and reliability of the application of the magnetotelluric method to the survey of magmatic rock and metamorphic rock formations in highway tunnels.

\section{Project Overview}

\subsection{Introduction to the geographic location of the study area}

The entrance of the tunnel is located near the Mupi Tibetan Township Government of Pingwu County, Mianyang City, Sichuan Province, China, as is shown in Fig. 1a. The exit is located in Jinfeng Village, Mupi Township, Pingwu County, on the left bank of Huoxi River. The exit is close to Huaneng Yinping Hydropower Plant. There is no road connection between the entrance and exit. The S205 road is about 100-300m away from the entrance of the tunnel, so the traffic is relatively inconvenient.

The proposed Mupi highway tunnel is left and right separated. The left tunnel design is shown in Fig. 1b. The starting and ending pile numbers of the left line are: ZK124+351 ZK126+502, the length is $2151 \mathrm{~m}$, and the maximum buried depth is $707 \mathrm{~m}$; the starting and ending pile numbers of the right line are: $\mathrm{K} 124+355 \sim \mathrm{K} 126+482,2127$, the maximum buried depth is $654 \mathrm{~m}$.
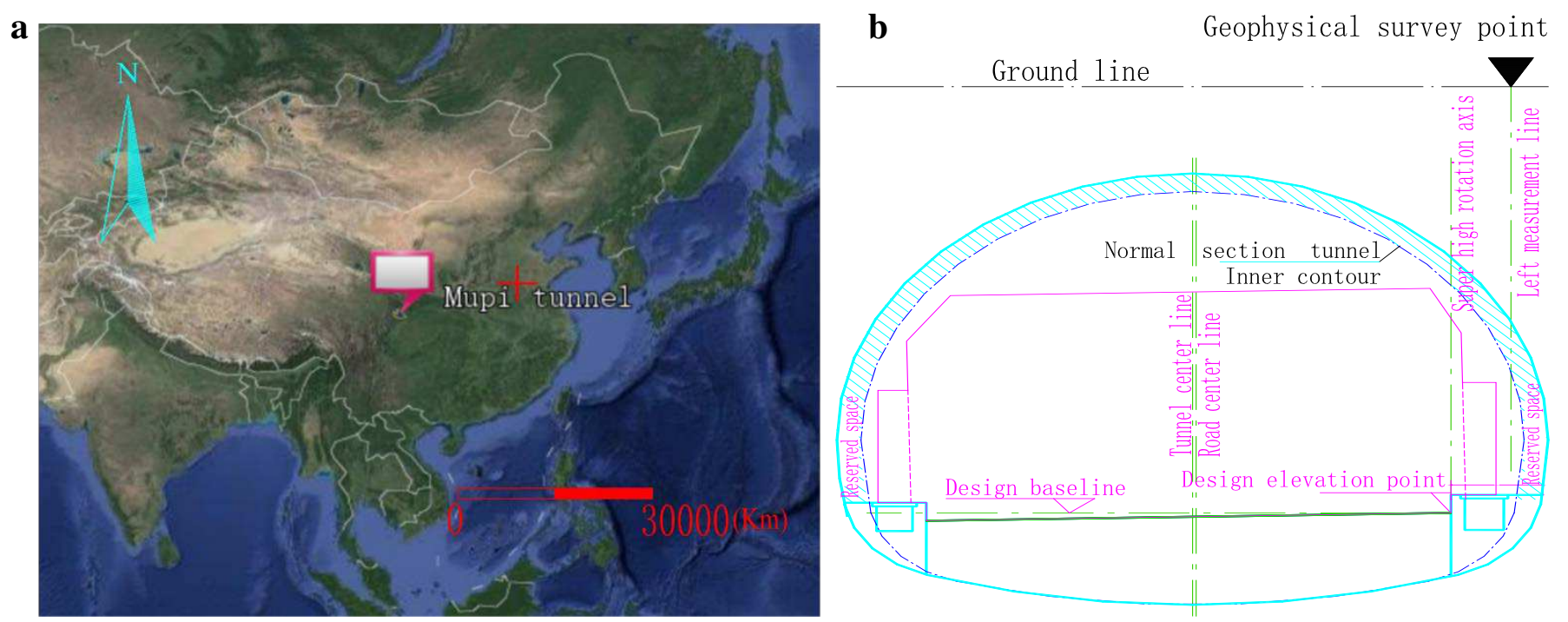

Figure 1. Location of the research area. (a) Location of the research area and geological survey. (b) Schematic diagram of Mupi tunnel design and Geophysical survey points. The map is based on Google satellite image, showing the location of the research area. The legend and other line in the map were created using AutoCAD version 2021 (https://www.autodesk.com) and CorelDRAW version 2021 (https://www.coreldraw.com).

\subsection{Overview of topography and geology in the study area}

The site is located on the east side of the Qinghai-Tibet Plateau, the Motianling mountain system, with steep mountains, complex topography, dense vegetation on the surface, and tectonic denudation of mid-mountainous landforms with large topography, as shown in Fig. 2a, c.

The tunnel is located on a wedge-shaped block bounded by the Wenxian arc-shaped structural belt in the north, the Minjiang-Xueshan-Huyaguan fault zone in the west, and the Longmenshan fault zone in the southeast. The tectonic traces in the block are mainly controlled by the three above-mentioned tectonic belts, but in the later period, affected by the arc structure of Wenxian County, they all present a curved arc protruding southward. The Indosinian period was strongly squeezed by the SN-trending tectonic movement, and a series of near-EW-trending folds and faults formed the basic structure of the area.

The faults and folds in the work area are relatively developed and large in scale, extending from dozens to nearly a hundred kilometers. There are mainly large folds and fault structures such as the Daqiao syncline, the veneer inverted anticline, the Baima arc structure belt, and the Nanping anticline. The tunnel is located near the core of the veneer inverted anticline.

According to the ground geological survey and the drilling revealed, the main lithology of the project area is gravel soil, Mupishaizi intrusion (TJS), and Dashaba formation (AnZd).

Dashaba Formation (AnZd): The lithology is dominated by light gray to dark gray garnet metamorphic porphyritic mica nachoschist, chlorite nachoschist, and biotite sericite schist, with a small amount of metamorphic sandstone and quartz veins, and the thickness is greater than 540m. See Fig. $2 \mathrm{~b}$ for details.

Mupishaizi intrusive (TJS): mainly medium to fine-grained biotite quartz diorite, gray to off-white, the mineral composition is mainly quartz, followed by diorite and biotite, granular cryptocrystalline structure, massive structure, the rock is hard. Local granodiorite or granite. See Fig. 2c, d, Fig. 9.

The groundwater in the tunnel site is mainly composed of loose accumulation layer pore water and bedrock fissure water. 
104

105

106

107

108

109

110

111

112

113

114

115

116

117

118

119

120

121

122

123

124

125

126

127

128

129

130

131

132

133

134

135

136

137

138

139

140

141

142

143

144

145

146

147

148

149

150

151

152

153

154

155

156

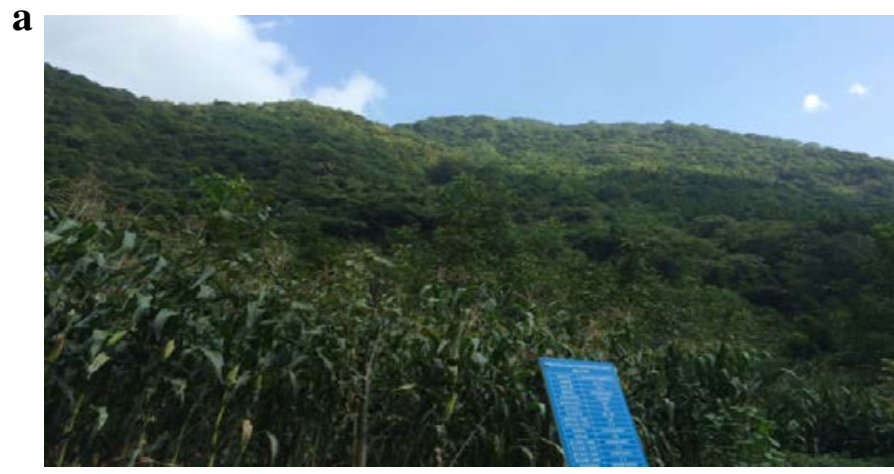

b
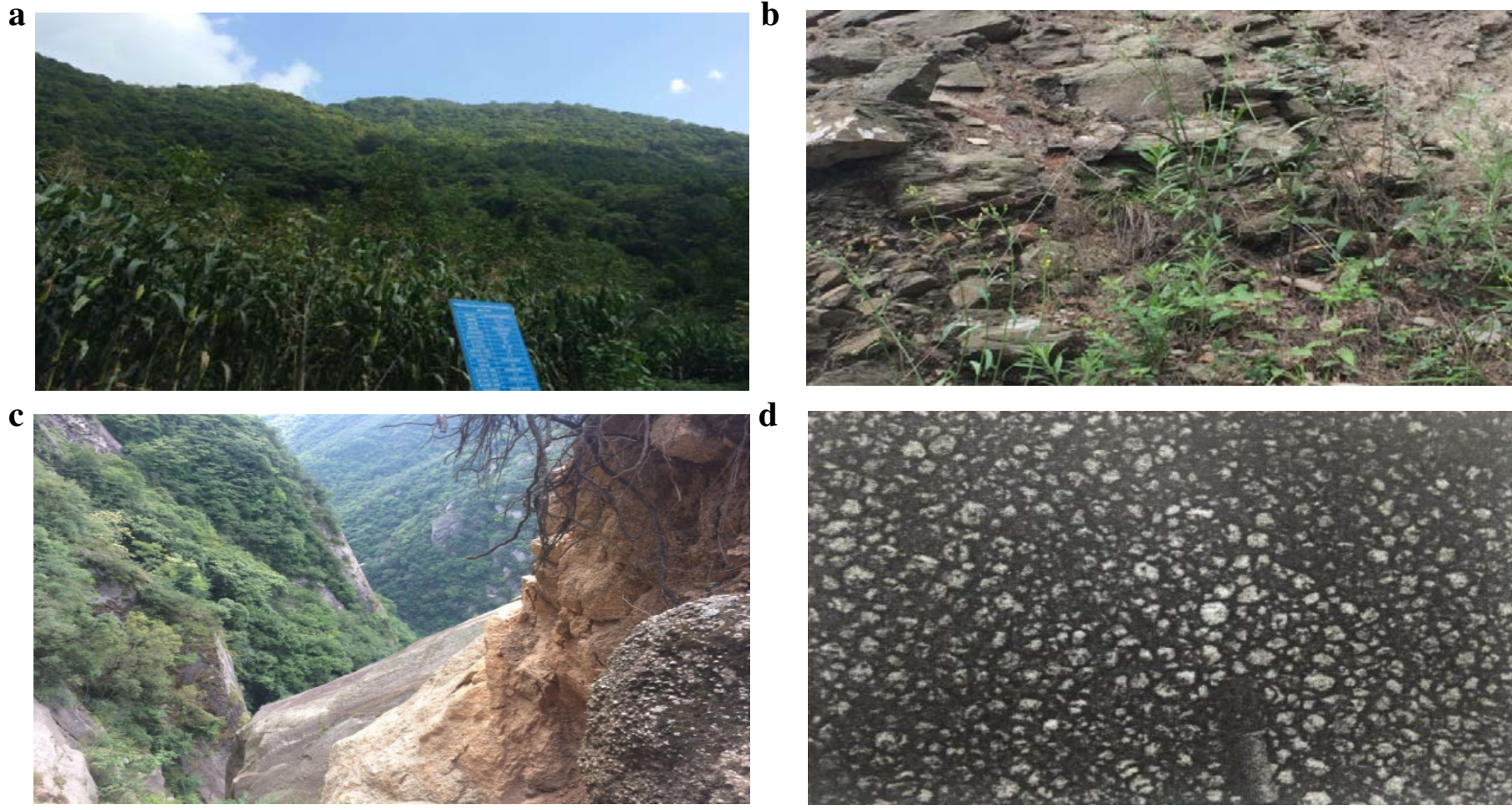

d

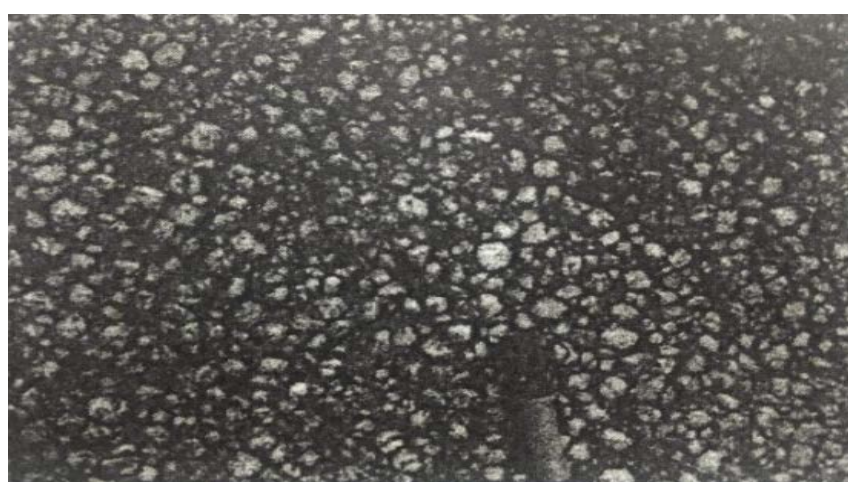

Figure 2. Topography and surface lithology photos of Mupi Tunnel. (a) Topographic photos of the entrance of the Mupi tunnel. (b) Lithology photo of the stratum at the entrance of Mupi Tunnel. (c) Lithology photo of the surface of the middle section of the Mupi Tunnel. (d) Mupishaiziyan photo. The right corner of the photo (c) is the Mupishaiziyan, and the picture (d) is taken after magnifying several times.

3. Data acquisition, processing and inversion

\subsection{Geophysical methods and survey line layout}

Magnetotelluric (MT) method is selected for geophysical exploration of Mupi tunnel. The work entered the site for survey on August 12, 2016, and formally entered the site on August 13, overcoming the complex terrain conditions and harsh environment, and successfully ending the field work on August 17.

In this geophysical exploration work, a survey line is arranged along the axis ZK124+670 ZK125+330 of the highway tunnel survey line (Fig. 1b, 3). The survey line is $660 \mathrm{~m}$ long and the measuring point distance is mainly $30 \mathrm{~m}$.

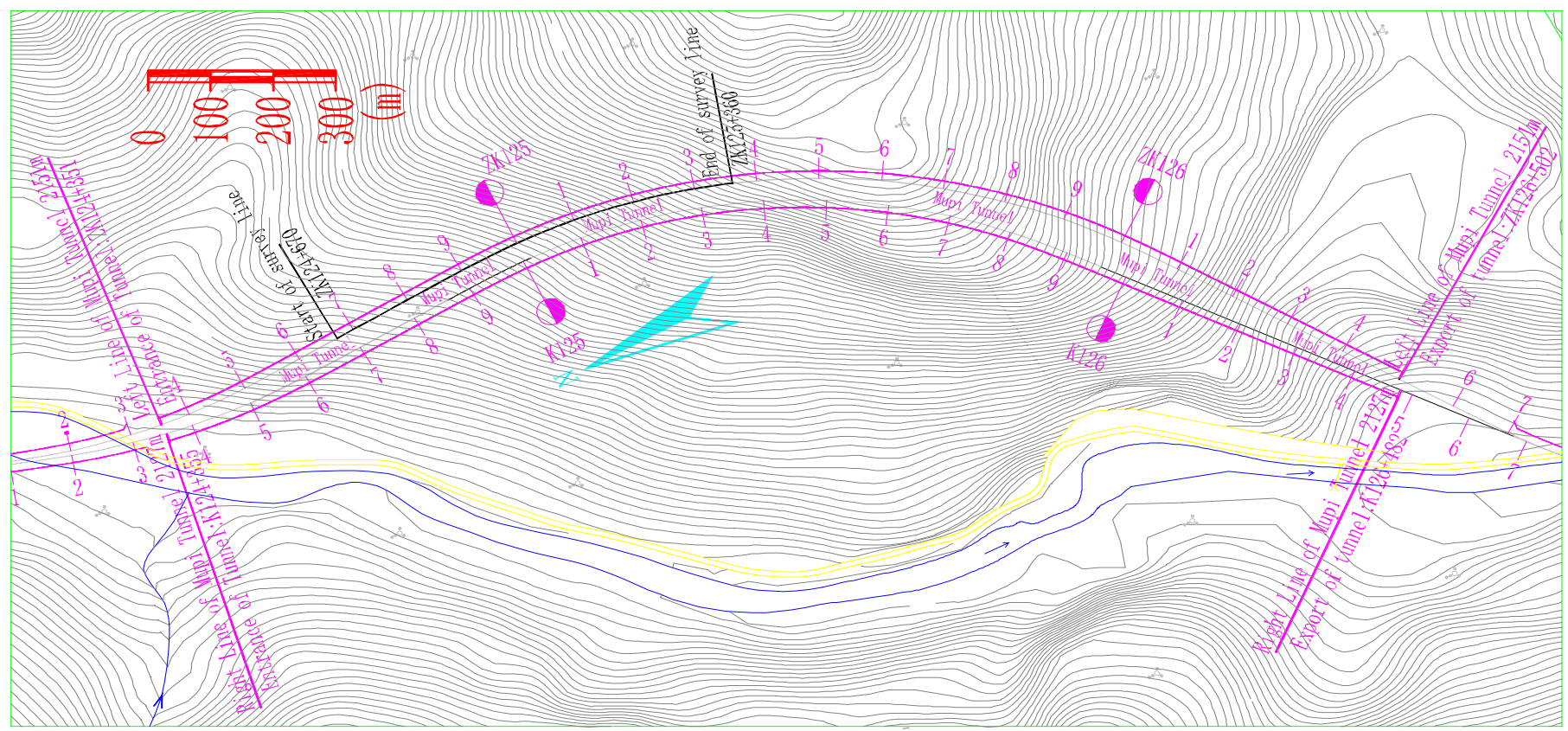

Figure 3. Layout Plan of Magnetotelluric Survey Line for Mupi Tunnel. The measurement line is arranged along the measurement line of the left hole of the Mupi Tunnel, as shown in Fig. 1 b, the distance between the measurement line 
The focus of the survey is to explore the engineering geological conditions from the ground to $50 \mathrm{~m}$ below the tunnel elevation, especially the contact boundary between magmatic rock and metamorphic rock, so as to provide reliable basis for engineering geological survey and detailed basic information for tunnel design.

\subsection{Mathematical Model of MT method for Highway Tunnel}

Assuming that the magnetic field is the input signal and the electric field is the output signal, the correlation between the magnetic field and the electric field signal is shown in the figure below (Fig. 4). Using the electric and magnetic signals from the surface observations to analyze the signals in the relevant domains, the mathematic model of the magnetotelluric method for the geological body of the proposed Mupi tunnel can be obtained.

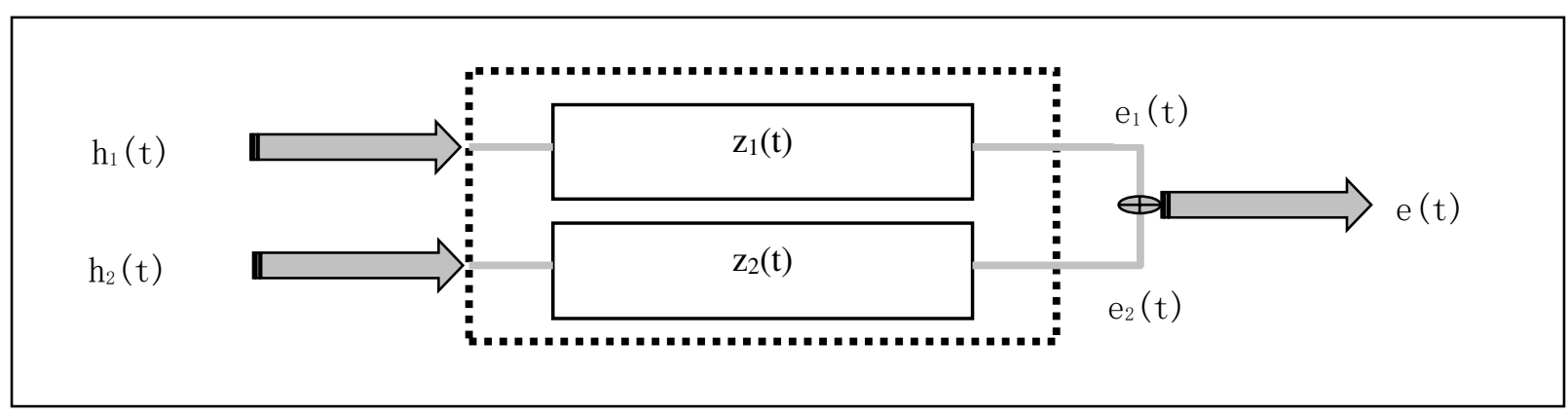

\section{Figure 4. Mathematical Model of Magnetotelluric Method for Highway Tunnel.}

$z(t)$ is the time factor of the rock and soil. The mathematical model of highway tunnel in magnetotelluric method can be described by the following formula ,3-1 is the Formula in time domain, and 3-2 is the Formula in frequency domain ${ }^{6,11}$ :

$$
\begin{gathered}
\mathrm{e}(\mathrm{t})=\mathrm{e}\left(\mathrm{t}_{1}\right)+\mathrm{e}\left(\mathrm{t}_{2}\right)=\int_{-\infty}^{\infty}\left[\mathrm{Z}_{1}(\xi) \mathrm{h}_{1}(\mathrm{t}-\xi)+\mathrm{Z}_{2}(\xi) \mathrm{h}_{2}(\mathrm{t}-\xi)\right] \mathrm{d} \xi \\
{\left[\begin{array}{l}
\mathrm{E}_{\mathrm{X}} \\
\mathrm{E}_{\mathrm{y}}
\end{array}\right]=\left[\begin{array}{ll}
\mathrm{Z}_{\mathrm{xx}} & \mathrm{Z}_{\mathrm{xy}} \\
\mathrm{Z}_{\mathrm{yx}} & \mathrm{Z}_{\mathrm{yy}}
\end{array}\right]\left[\begin{array}{l}
\mathrm{H}_{\mathrm{x}} \\
\mathrm{H}_{\mathrm{y}}
\end{array}\right]}
\end{gathered}
$$

Introduce the definition of the plane electromagnetic wave impedance and then it can be obtained (the detailed process can be seen in Reference ${ }^{7-12}$ ):

$$
\rho=\frac{1}{\omega \mu}|\mathrm{Z}|^{2}
$$

The above formula shows that the electrical resistivity of the tunnel can be calculated by measuring the orthogonal horizontal component of the electromagnetic field on the surface.

When $\mu=\mu_{0}=4 \pi \times 10^{-7} H / M, \omega=\frac{2 \pi}{T}, E(m v / k m), H(\gamma)$, taking the practical unit system, the above formula can be written as:

$$
\rho=\frac{1}{\omega \mu}|\mathrm{Z}|^{2}
$$

The above formula 3-4 characterizes the relationship between the surface electromagnetic measurement value of the highway tunnel under the condition of uniform isotropic medium and the apparent resistivity of the tunnel site. It is a comprehensive feature of the surrounding rock of the tunnel, including the lithology, structure and groundwater of the surrounding rock and other information of the tunnel.

\subsection{Data acquisition and quality assurance}

Before the formal work started, the regional geological data was collected, and the electrical parameters of the work area

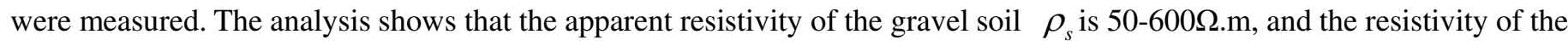
complete schist and diorite is $\rho_{s}>3100 \Omega$.m. Have the prerequisites for highway tunnel survey.

This work uses the V8 multi-function electrical method produced by Phoenix, Canada, and collects and arranges two orthogonal electromagnetic field information on the ground at a certain distance (this exploration is mainly $30 \mathrm{~m}$ ), that is, point by point on the survey line. Measure the four-component Ex, Hy or Ey, Hx parameters of the electromagnetic field. This work 
collects natural electromagnetic fields with a frequency between $10-10000 \mathrm{~Hz}$, and the average acquisition time for each measuring point is about 15 minutes, and the exploration depth is controlled within $700 \mathrm{~m}$. Due to insufficient collection time, some data in the low frequency range is messy, and the overall goal is to balance efficiency and quality.

The V8 magnetotelluric data is preprocessed by the SSMT 2000 software provided by Canadian Phoenix Company. The time series signal is fast Fourier transformed to obtain the magnetotelluric field self- and cross-power spectrum. The software uses robust processing technology ${ }^{20}$ to estimate the tensor impedance.

Data acquisition is strictly implemented in accordance with the relevant regulations of highway geophysical prospecting to ensure the reliability of the original data, the tunnel construction also verified the reliability of the data. The typical data curve is shown in Fig. 5.

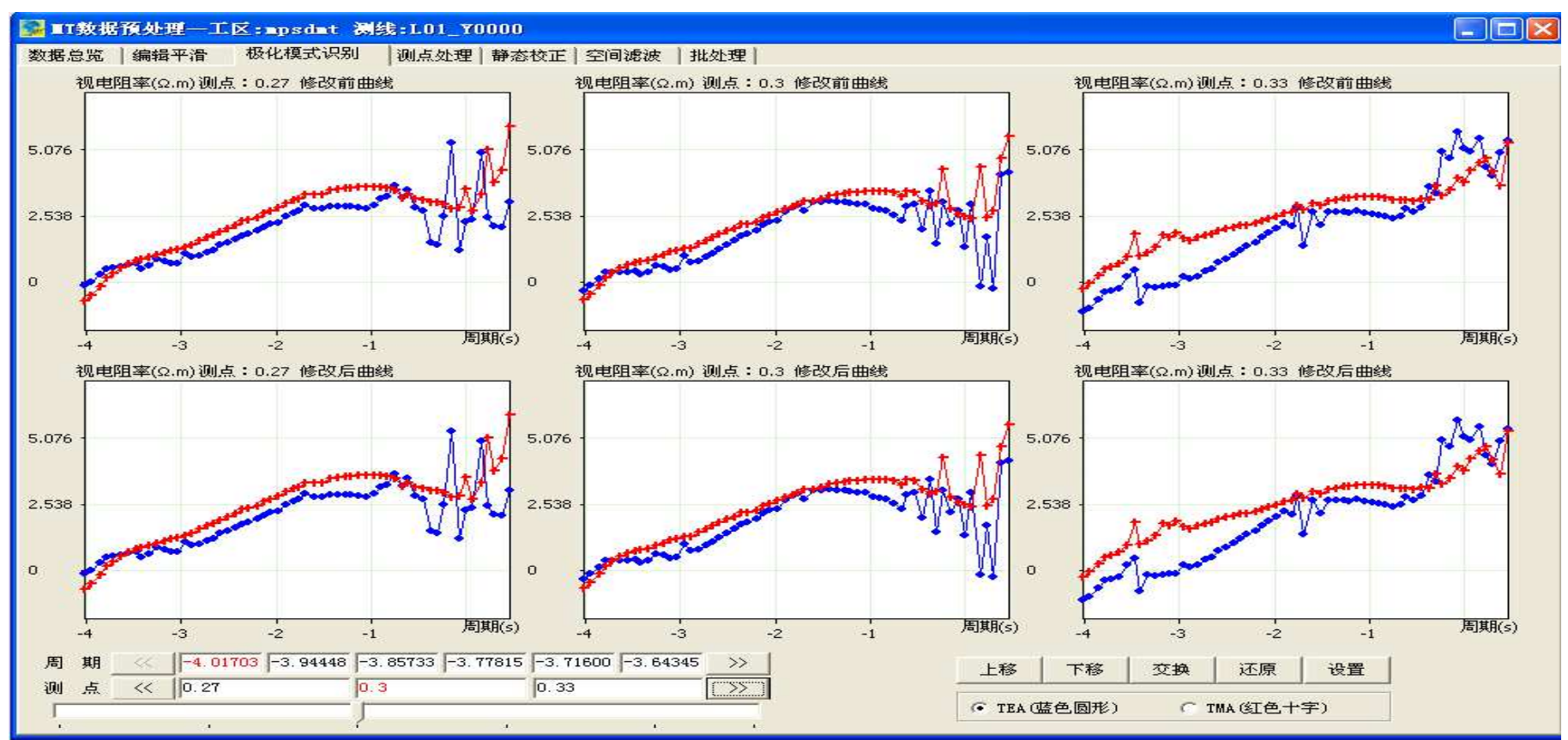

Figure 5. MT data of Mupi tunnel (TE mode apparent resistivity, section $0.27-0.33 \mathrm{~km}$, point ZK124+850,880,910).

\section{Inversion}

\subsection{1-D inversion}

In magnetotelluric field data collection, in addition to visual observation and recording of raw data such as time domain, frequency domain, and power spectrum domain, some instruments can quickly obtain a 1-dimensional inversion map of a single measurement point. If the instrument does not have this function, you can After the acquisition is completed, the data is imported and processed by the computer, and the commonly used one-dimensional BOSTIC inversion, OCCAM inversion ${ }^{14}$, etc. Fig. 6 shows a one-dimensional inversion diagram of the Mupi Tunnel ZK124+670 measuring point, which can be seen directly. If it is assumed to be a three-layer geoelectric model, this data curve is a typical high-low-high H-shaped.
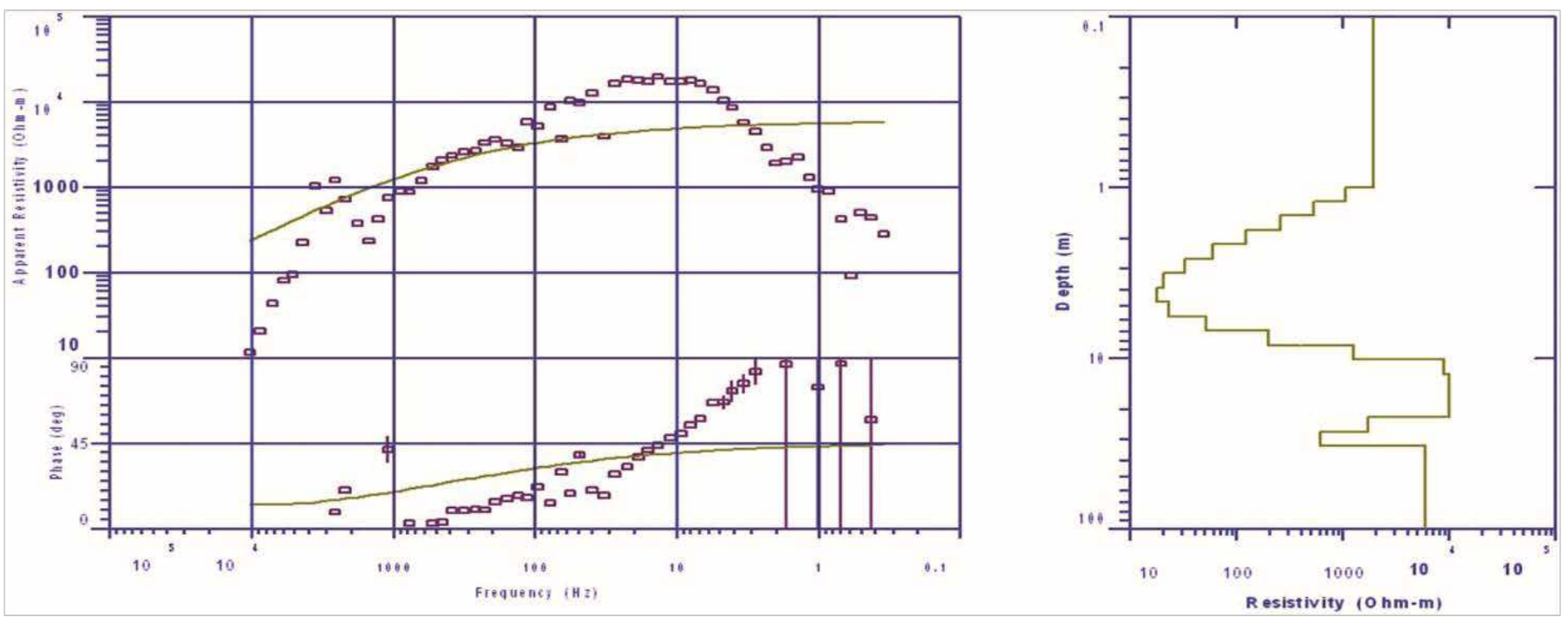

Figure 6. 1D inversion map of ZK124+670 measuring points of Mupi Tunnel. 
The investigation's internal work use the magnetotelluric processing and interpretation system (MTSoft2D-2.3V) developed by the Key Laboratory of Earth Exploration and Information Technology of the Ministry of Education (Chengdu University of Technology) for subsequent data processing and inversion interpretation. The tunnel may cross the lithological boundary between metamorphic rock and magmatic rock. A variety of inversion methods (including two-dimensional Bostick, Occam ${ }^{13,16,17}$, RRI ${ }^{14}, \mathrm{NLCG}^{15}$, et.al.) are used to compare and analyze the pre-processed data, and two-dimensional Occam inversion is selected. The method of Occam inversion, the corresponding inversion parameters and results are regarded as the final processing results.

Other inversion methods are also similar processes. After selecting a suitable inversion model, the apparent resistivity contour profile of the inversion model can be drawn, as shown in Fig. 7. The same process can also be used to obtain the phase contour profile.
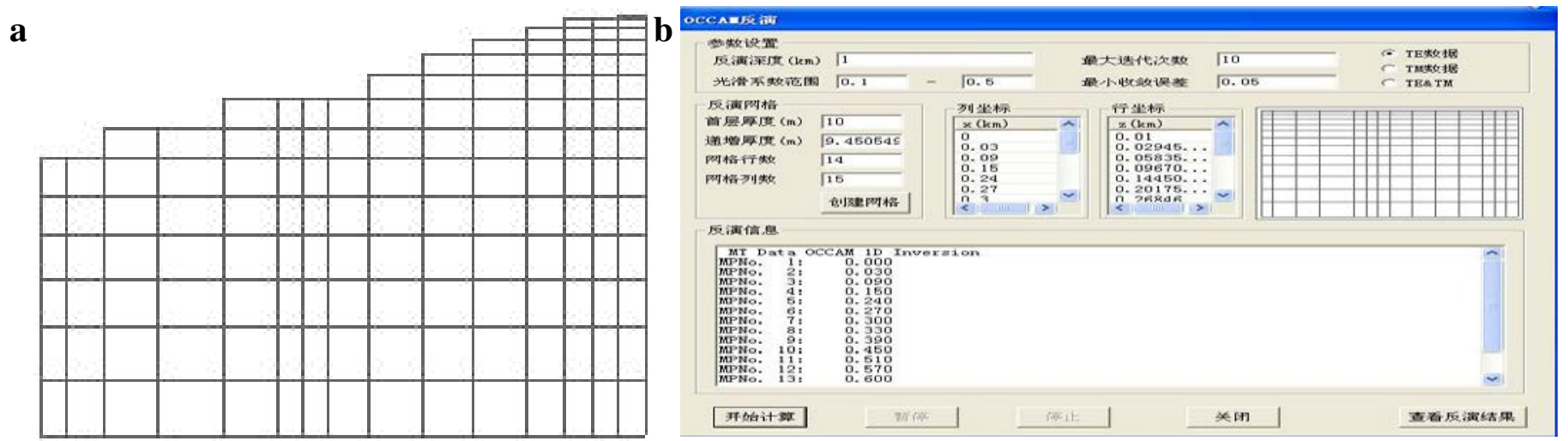

c

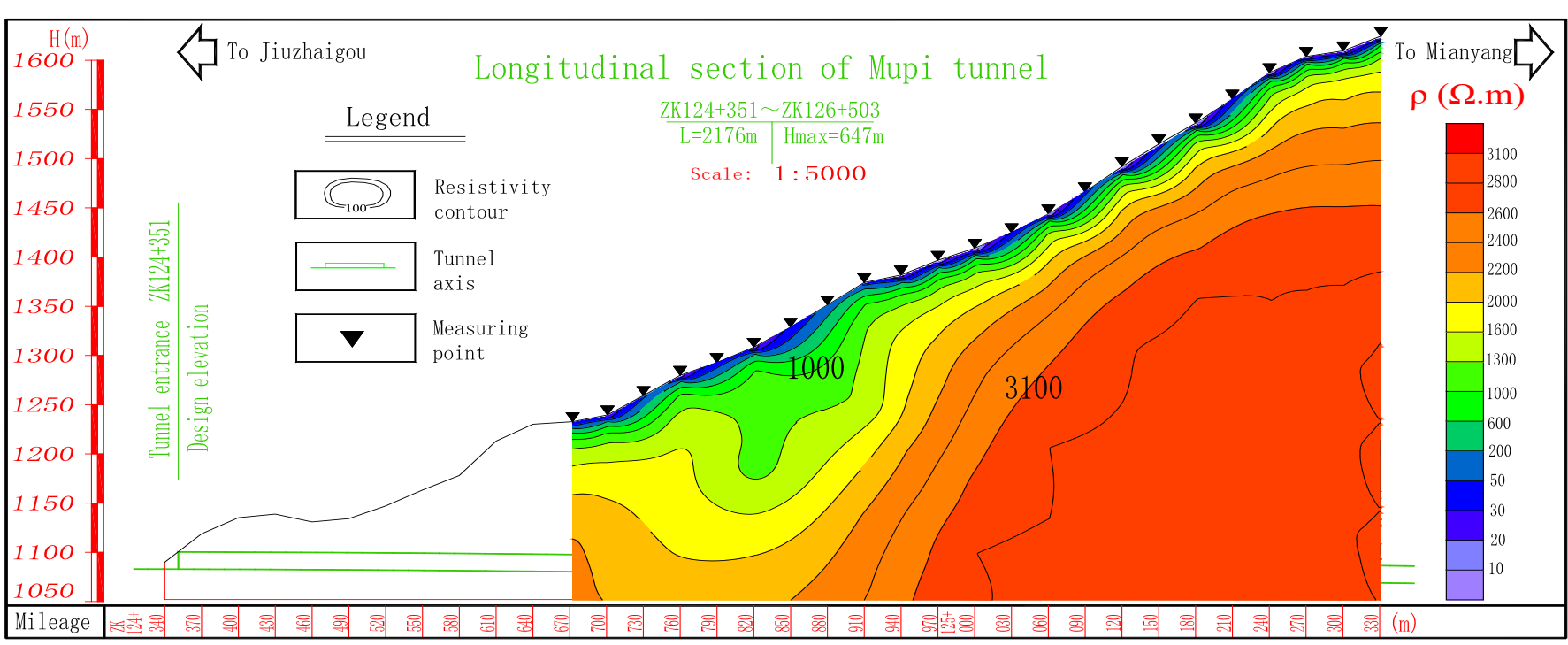

Figure 7. Mupi tunnel inversion map. (a) Occam inversion grid division (b) Occam inversion parameter selection (c) Occam inversion apparent resistivity contour map

\section{Conclusion and discussion}

\subsection{Geological interpretation results inferred based on the electrical characteristics of MT}

After selecting a suitable inversion model and drawing the apparent resistivity contour profile of the inversion model, on this basis, refer to the 1:200,000 regional geological data (Pingwu sheet) and the results of the previous geological survey to complete the preliminary Mupi tunnel, the electrical properties profile is shown in Fig. 8a.

After discussing with geologists to determine the intrusion method of the magmatic rock intrusion ${ }^{27}$, it is clear that the emplacement mechanism is mainly the passive emplacement rock wall expansion method, and then the electrical characteristic profile is modified. And its electrical characteristics model geological interpretation, see Fig. 8b.

1. The ZK124+670 ZK125+030 section of the tunnel, the apparent resistivity value is $\rho=1300 \sim 3100 \Omega$.m, combined with the geological data, it is inferred to be the electrical performance of the metamorphic rock mass. The rock mass in this section is broken and weak with water. At ZK125+030, the resistivity gradient has the largest lateral change, which is presumed to be the boundary between metamorphic rock and magmatic rock. Combined with the occurrence of metamorphic rock exposed on the surface, the maximum gradient direction of the resistivity curve is inferred to be the contact direction of magmatic rock and metamorphic rock. 
2. The section of the tunnel body from ZK125+030 to the exit of the tunnel, the resistivity value $\rho>3100 \Omega . m$, combined with geological data, it is inferred to be the electrical performance of the magmatic rock mass. The rock mass in this section is relatively broken and weak.

3. At ZK125+030, the resistivity gradient has the largest lateral change, which is presumed to be the boundary between metamorphic rock and magmatic rock. Combined with the occurrence of metamorphic rock exposed on the surface, the direction of the maximum gradient of the resistivity curve cluster is inferred to be the contact relationship and direction of magmatic rock and metamorphic rock.

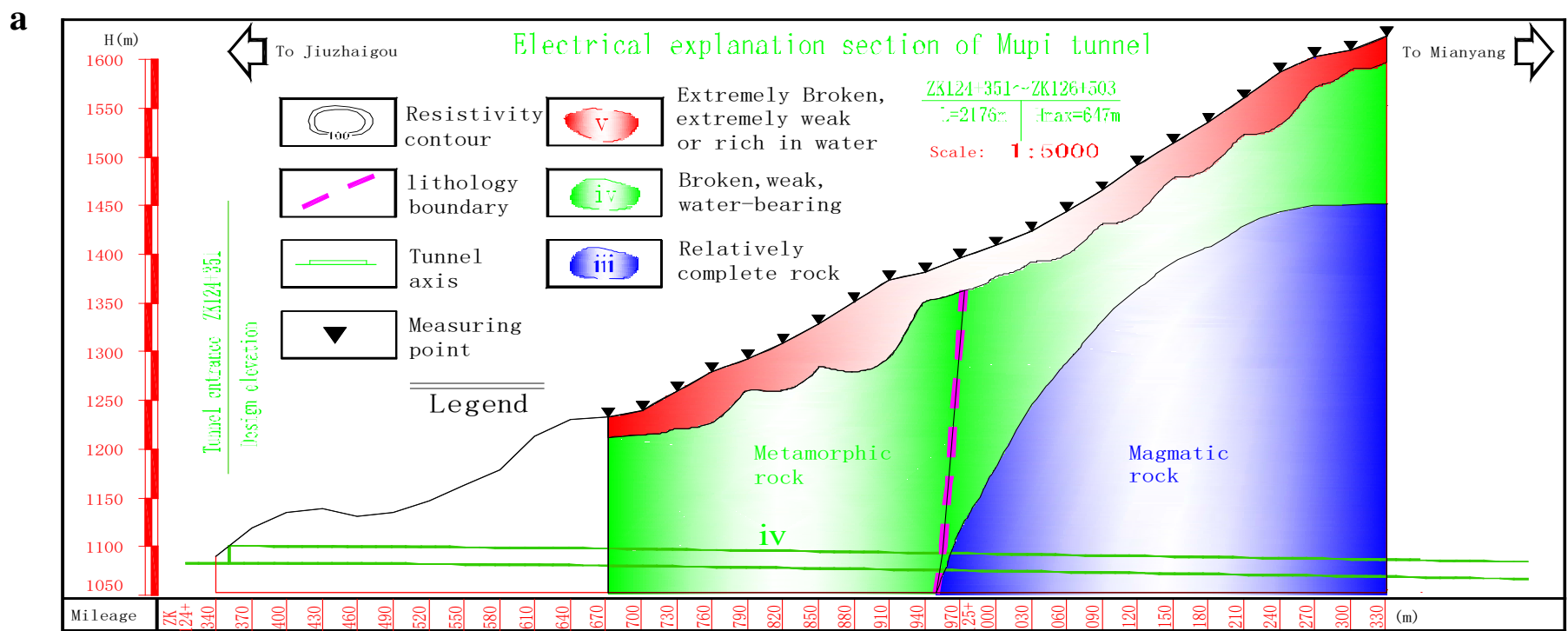

b

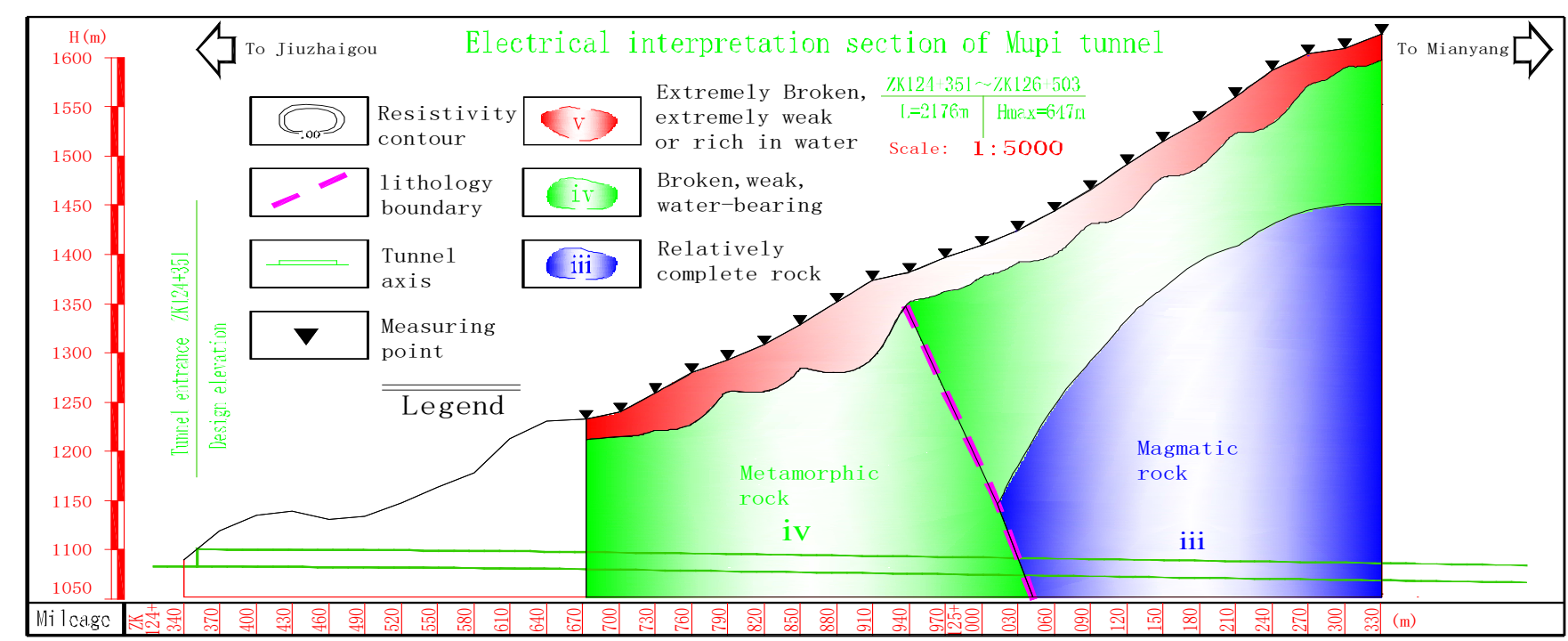

Figure 8. Mupi Tunnel Electrical Geological Interpretation Section. (a) Preliminary electrical geological interpretation profile. (b) Comprehensive geological results, considering the occurrence of metamorphic rocks and magmatic rock intrusions, modified electrical geological interpretation section.

\subsection{Validation of electrical model}

In order to complete the application research of magnetotelluric in the investigation of magmatic rock intrusions, with the help of the later service of Mupi Tunnel, the actual excavation data of the tunnel was collected, and comparative analysis was carried out, and the inversion and interpretation work was further iterated again.

The design (geological survey) and construction excavation have relatively few changes. The design (geological survey) work is relatively conservative and the overall control is better.

The whole Mupi Tunnel has been completed in the early period of the Spring Festival in 2020, and it has been completed and accepted.

Now give the lithological boundary identification verification of the tunnel construction excavation, and give the success and shortcomings of the geophysical interpretation:

1. Identification of the boundary between metamorphic rock and magmatic rock (mupishaiziyan intrusion):

The actual excavation of the Mupi Tunnel is about 50 meters ahead of the design (geological exploration) of the magmatic rock (Mupishaiziyan intrusion), namely ZK125+024.2. The original geological survey is slightly conservative. The original geophysical prospecting speculated that ZK125+030, where the resistivity gradient changes the most horizontally, was the 
boundary between metamorphic rock and magmatic rock, which verified the correctness of the inversion method and electrical interpretation. Excavation of the magmatic rock (mupishaiziyan intrusion) is shown in Fig. 9. However, the magmatic rock intrusion interface has a large water gushing during tunnel construction, so the level of surrounding rock has not been changed, and the overall design and geological survey are well controlled.

2. Insufficiency of geophysical exploration

Although the analysis and prediction of rock burst is not the focus of the original survey, but the problem of rock burst during the construction of the Mupi tunnel is not mentioned in the original survey report, and it is still insufficient. The analysis and prediction of rock burst ${ }^{26}$ in the survey and design stage by the magnetotelluric method needs further study.

\section{a}

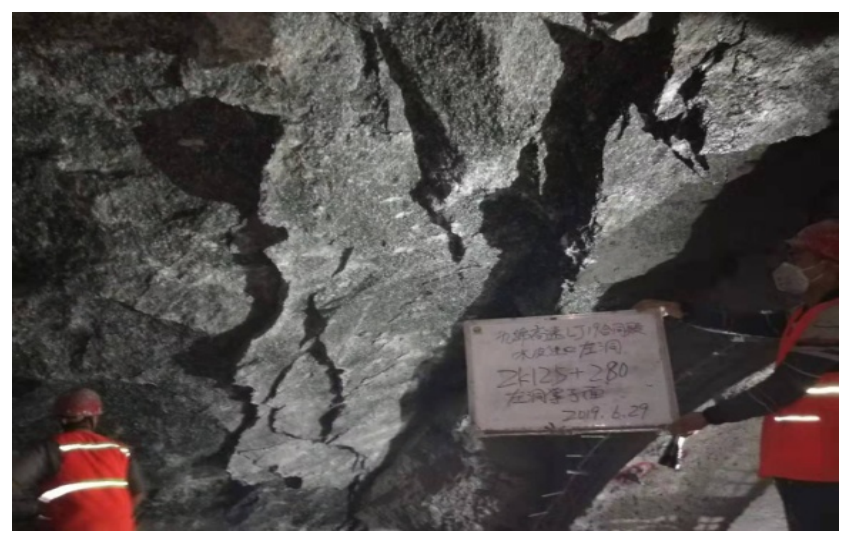

c

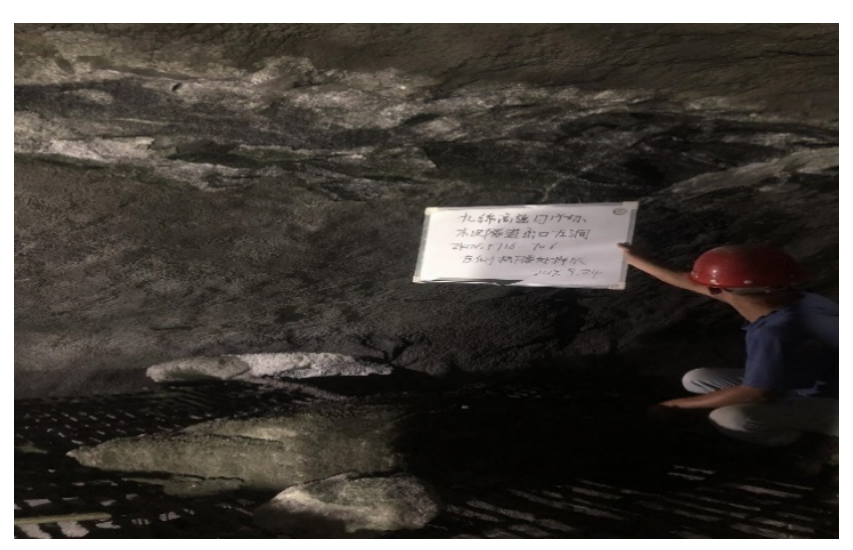

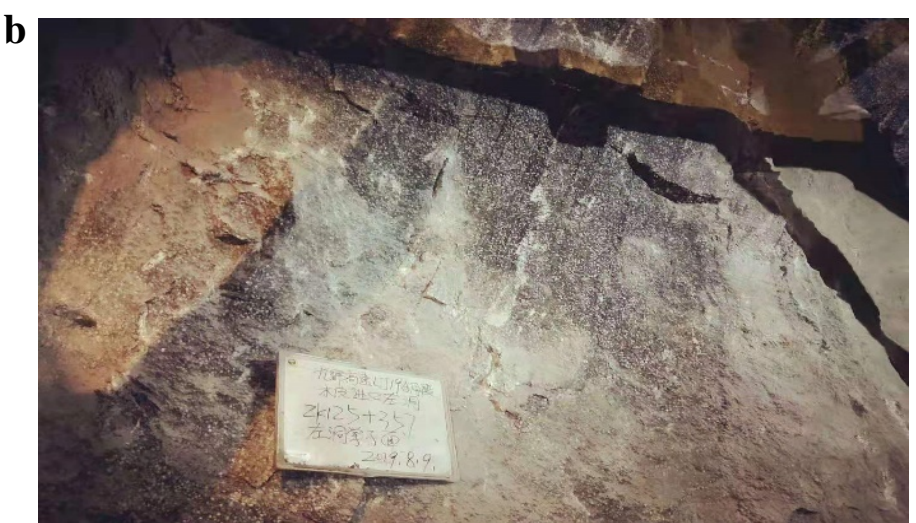

d

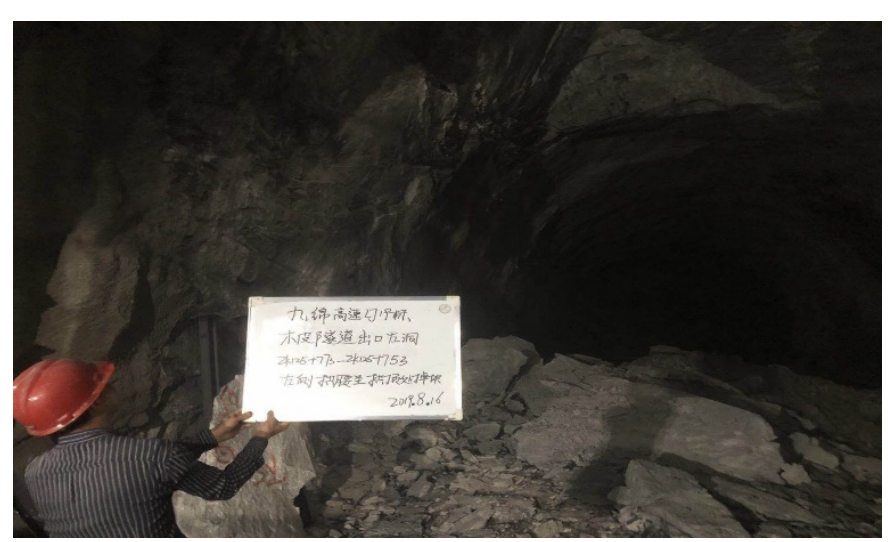

Figure 9. Mupi tunnel construction photos. (a) Mupi left hole ZK125+234 surrounding rock photos. (b) ZK125+280 tunnel face surrounding rock photos. (c) ZK125+706-716 left side arch waist surrounding rock falling photos. (d) ZK125 +773 Photos of the left arch from the waist to the top of the vault.

\subsection{2-D Forward Numerical Simulation of Mupi Tunnel by Magnetotelluric Method}

Based on the topographic and lithological characteristics of the Mupi Tunnel, this study abstracted a typical electrical model for numerical simulation ${ }^{8-12}$, and generated a two-dimensional profile corresponding to the apparent resistivity and phase, as shown in Fig. 10.

The model is close to the actual undulating topography and the intrusive distribution of metamorphic rock and magmatic rock. As shown in Fig. 10a, the apparent resistivity of metamorphic rock schist is $1000 \Omega$.m, the apparent resistivity of magmatic rock diorite is $4500 \Omega . \mathrm{m}$, and the study area is $5 \mathrm{~km}$ long. It has a height of $3 \mathrm{~km}$ and a total of 100 measuring points. The measuring point distance is $50 \mathrm{~m}$. The calculated frequency points are 41 , which are evenly distributed with equal logarithmic intervals between $10-10 \mathrm{~K} \mathrm{~Hz}$.

Use self-compiled electromagnetic separation highway tunnel magnetotelluric exploration software (MT-T-Highway V1.0.0) to complete the forward numerical simulation calculation.

Fig. 10b is the apparent resistivity value, the abscissa is the frequency (unit is $\mathrm{Hz}$ ), the ordinate is the apparent resistivity value of the mode (the unit is $\Omega . \mathrm{m}$ ); Fig. 10c is the impedance phase diagram, and the abscissa is the frequency (unit is $\mathrm{Hz}$ ), and the ordinate is the impedance phase value of the mode (unit is ${ }^{\circ}$ ).

The forward numerical simulation calculation has a certain reference and guidance for the actual processing of the distribution characteristics of the magnetotelluric field caused by lithology, and then makes more reasonable judgments and geophysical inference interpretations that are closer to objective geological bodies.

For example, taking the dip angle of the lithological interface as an example, the phase map of the TE mode is closer to the geological model than the apparent resistivity map of the TE mode. Therefore, phase inversion can be added to the subsequent data processing and inversion maps, and the lithology interface can be inferred after comprehensive analysis. 
a $(\mathrm{Km})$

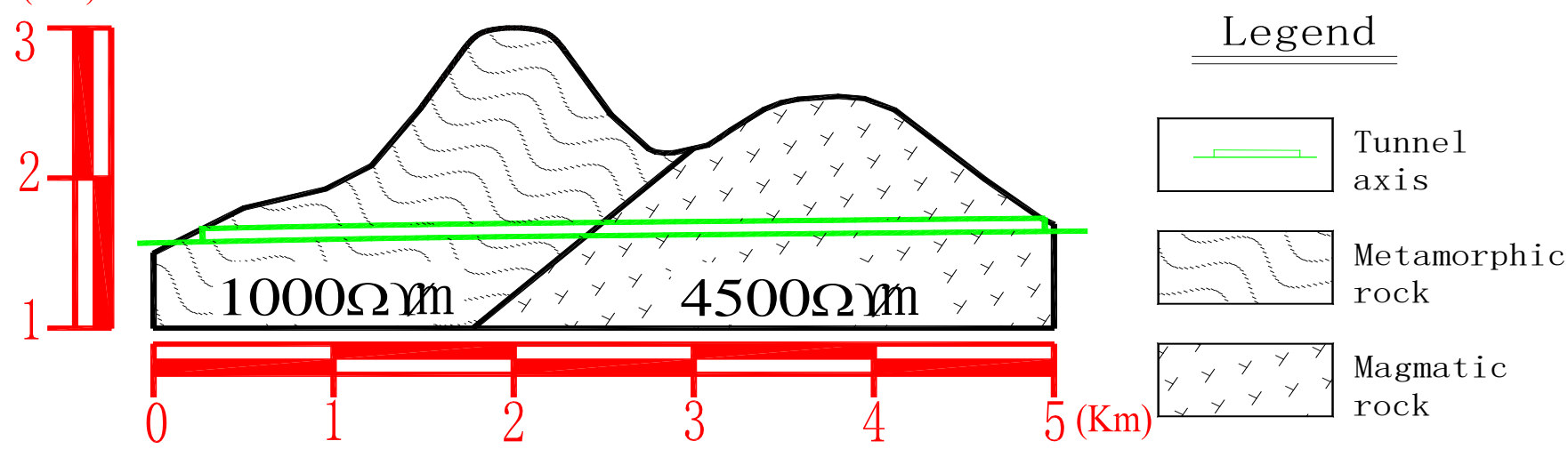

\section{b}

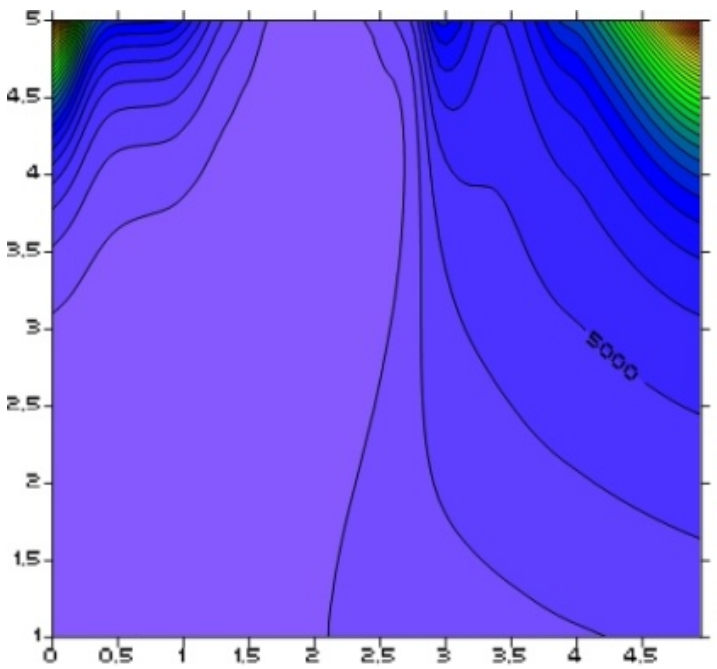

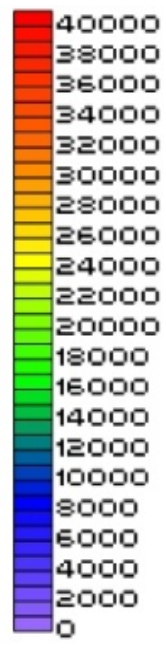
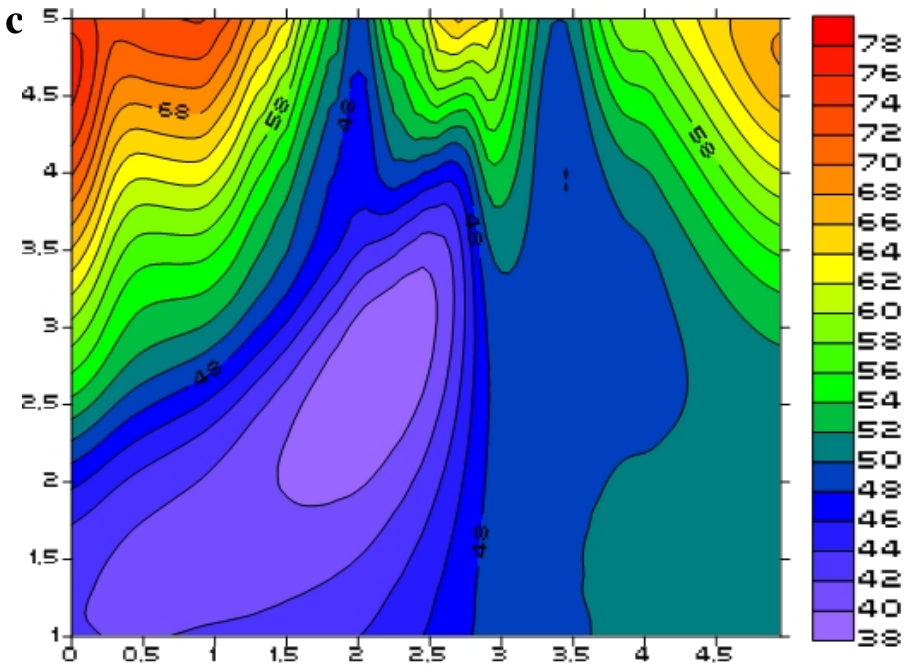

Figure 10. Magnetotelluric Forward Numerical Simulation of Mupi Tunnel. (a) Different lithology models of the undulating terrain of the tunnel. (b) TE mode apparent resistivity profile. (c) TE mode impedance phase profile.

\subsection{3-D inversion}

Based on the verification of the 2-D OCCAM inversion results during the tunnel construction, This research also tried to use 3-D inversion code by Egbert (2009), which had been parallelized for multiple frequencies. 23 points were used in the inversion to produce 3-D resistivity structures. The response of the final model is shown as determinant apparent resistivity (in Fig. 11). The observed and calculated responses fit will.

Fig. 11 shows representative depth sections. At depths of 1,2 and $3 \mathrm{~km}$ (Fig. 11a, b, c, respectively), the distribution of resistivity is consistent with the surface geology. Proved the effectiveness of 3-D inversion.

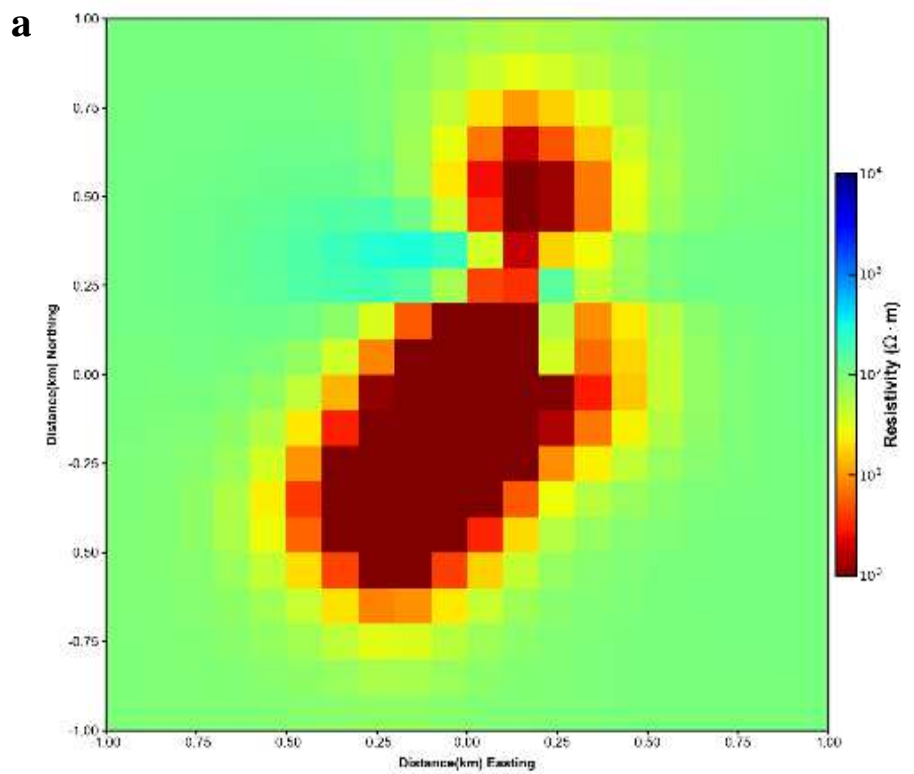

b

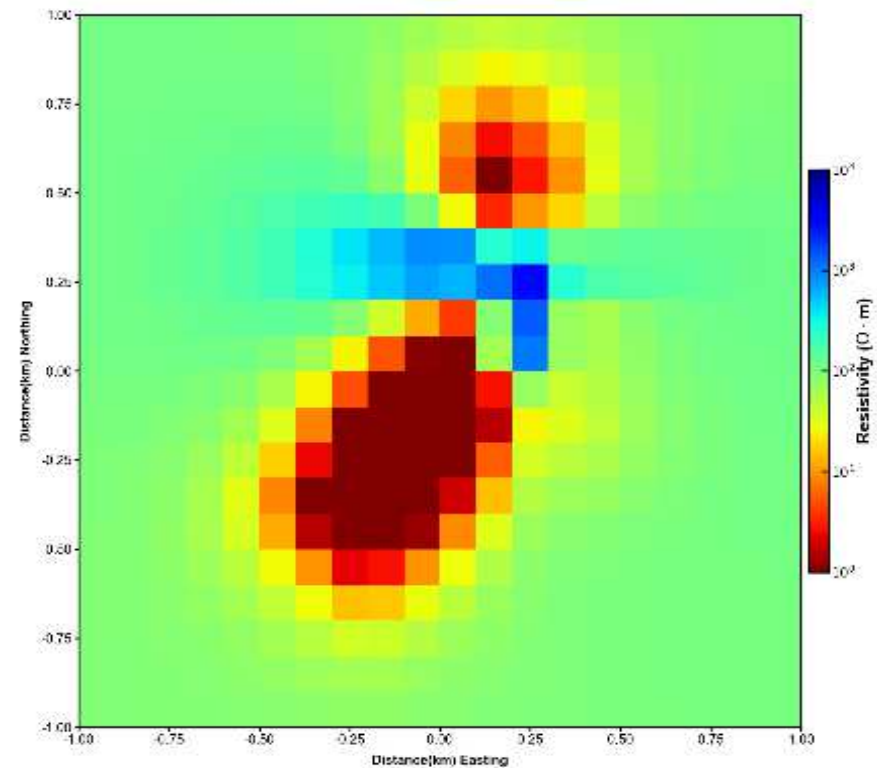


c

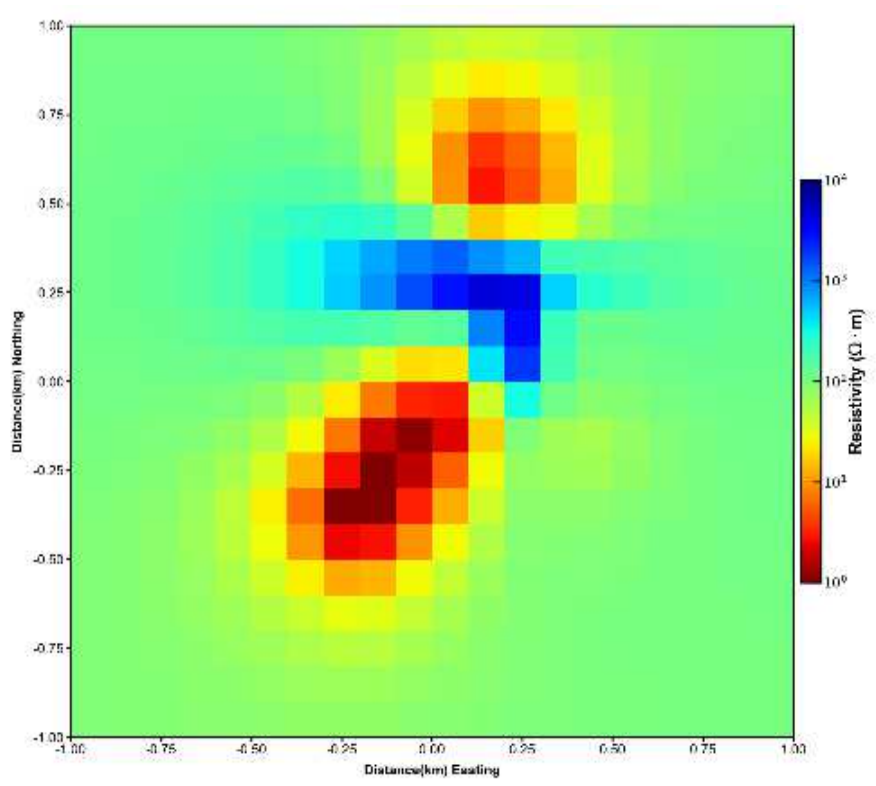

e

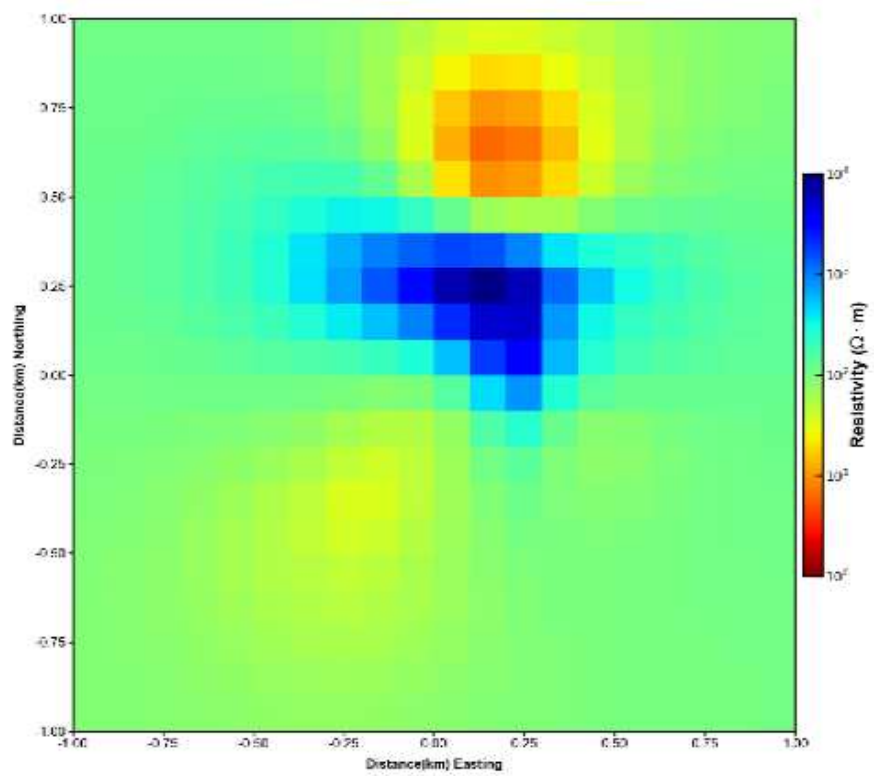

g

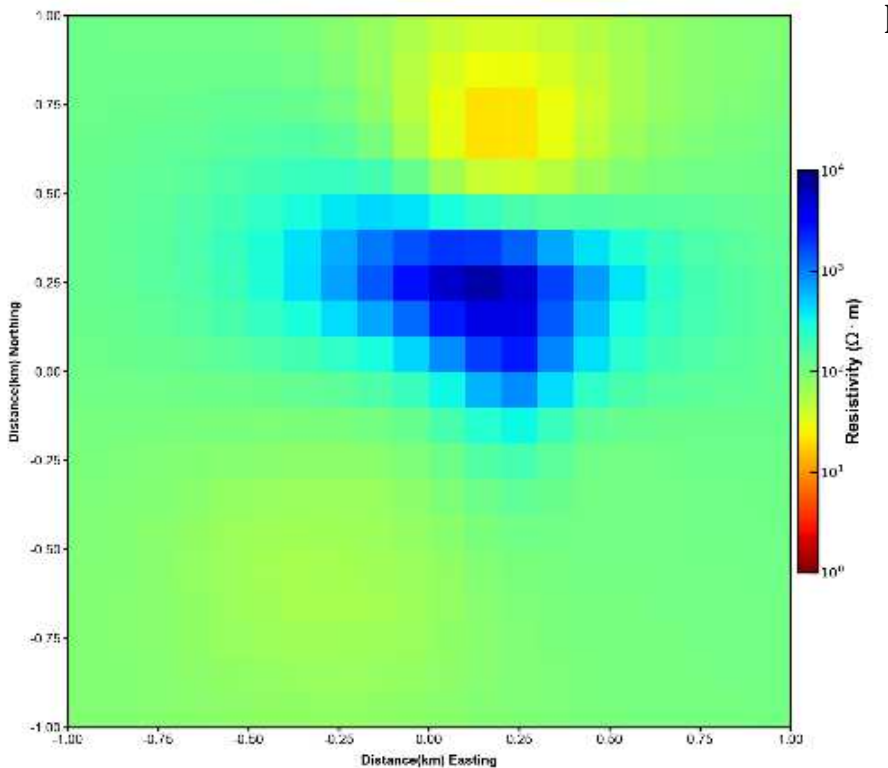

d

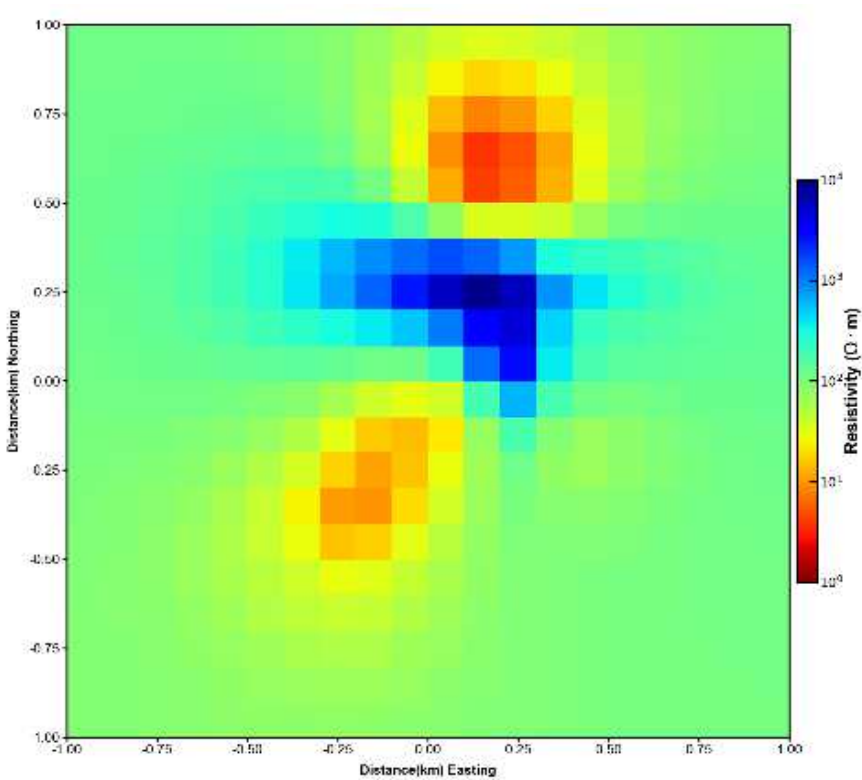

f

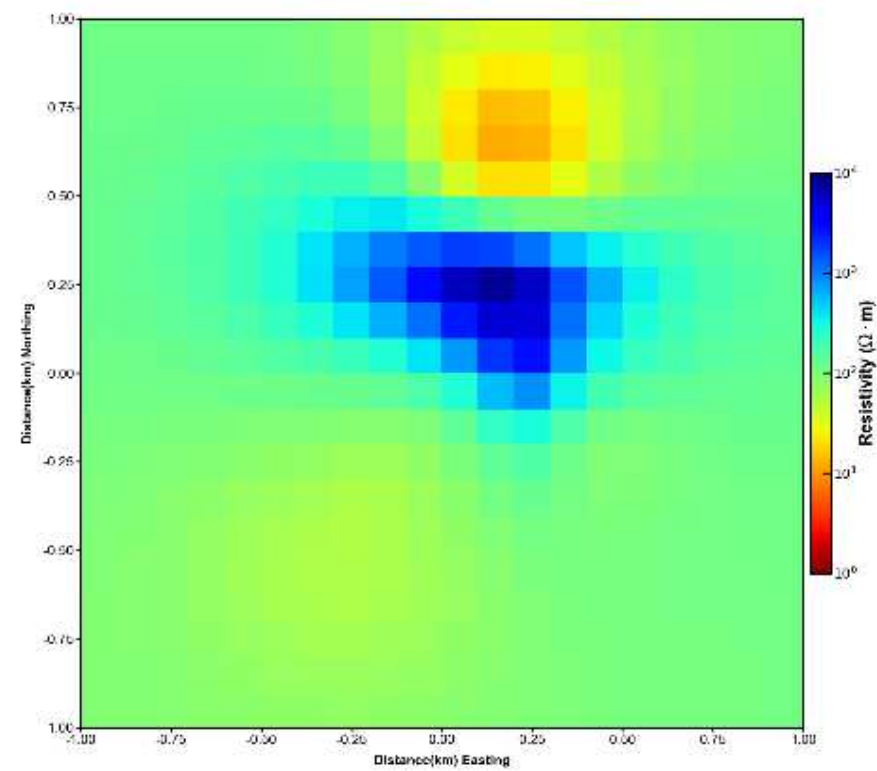

h

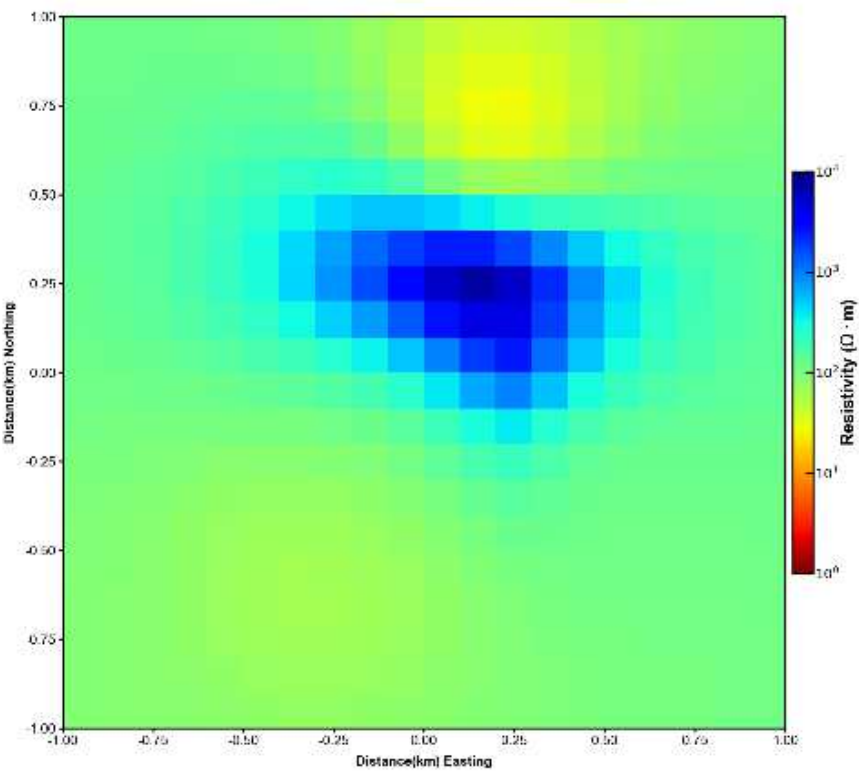

Figure 11. Three-dimensional inversion map of veneer tunnel. (a) N-E-plane-at-Depth $0 \mathrm{~km}$. (b) N-E-plane-at-Depth 1 km. (c) N-E-plane-at-Depth 2 km. (d) N-E-plane-at-Depth 3 km. (e) N-E-plane-at-Depth 4 km. (f) N-E-plane-at-Depth 5 km. (g) N-E-plane-at-Depth 6 km. (h) N-E-plane-at-Depth 7 km.

In the future tunnel inversion, 3-D inversion can be $\operatorname{tried}^{28}$, and the tunnel surrounding rock grade can be comprehensively 
estimated through the multi-dimensional inversion results such as 1-D, 2-D, and 3-D combined with the geological results.

\section{6. conclusion}

1. Through the data processing, inversion and interpretation of the magnetotelluric survey of the Mupi Tunnel of JiuzhaigouMianyang Highway on the G8513 Line, the electrical characteristics of each layer from the ground along the design line of the tunnel to the depth of 50m within the design elevation of the tunnel are revealed. Discussed the identification of the contact boundary between magmatic rock and metamorphic rock.

2. This study provides evidence of magnetotelluric sounding of the contact boundary between magmatic rock and metamorphic rock of the Mupi Tunnel, which is revealed by the excavation of the tunnel, which verifies the correctness of the geophysical inversion model, and verifies the geophysical data acquisition, data preprocessing, and inversion. The correctness of the performance method. Among them, the selection criteria of geophysical inversion methods and parameters are not unique. This preliminary explanation is obtained using two-dimensional Occam inversion this time, and it is not ruled out that other methods cannot obtain this model.

3. This study combines the geological results to give the tunnel electrical geological interpretation section, and the actual excavation of the tunnel verifies the correctness of the established electrical geological model. It can provide experience and lessons for the design and construction of tunnels with similar stratum lithology in the future.

4. This study also discussed the use of the finite element method to complete the magnetotelluric forward calculation based on the veneer tunnel model, and has an overall understanding of the electromagnetic field distribution characteristics under similar geological conditions.

5. Although the current general engineering survey processing software is mostly two-dimensional inversion, this research also discusses the inversion model that tries to use the three-dimensional finite difference method to explain the MT inversion of highway tunnels under complex geological conditions in the future. A meaningful attempt. The results of this research can continue to be carried out in depth, and do a good job of complementing scientific research, survey and tunnel construction, in order to provide a more efficient and accurate means of identifying the lithology boundary of intrusive magmatic rocks in metamorphic rocks for highway tunnel design.

\section{Acknowledgements}

This study is supported by National key R\&D plan (Grant No. 2018YFC1504901), National key R\&D plan (Grant No. 2018YFC1504904), Sichuan Transportation Science and Technology Project (Grant No.110102033) . We thank Egbert of Mahidole University for the WSINVMT3D code (Egbert 2009). We feel indebted to all the members of Sichuan Highway Planning, Survey, Design And Research Institute Ltd, Especially Yang Xubo, Xie Wei, Peng Hui and Zhang Bin for their help. Last but not least. Without their insightful instruction and heartfelt support, this paper would not have been completed.

\section{References}

1. H.K. Jahansen. Fast Hankel Transform Geophysical Prospecting[J]. (27):877-901.

2. Kneight $\mathrm{J} H$,Raiche A P. Electromagnetic calucation using the Gaver-Stehfest inverse Laplace transform method[J]. Geophysics, 1982,47(1):47-50.

3. Zohdy A A R. A new method for the interpretation of Schlumberger and Wenner sounding curves[J]. Geophysics, 1989,54(2):245-353.

4. Spies B R. Depth of investigation in electromagnetic sounding Methods[J]. Geophysics,1989,54(7):872-888.

5. Eaton P A.Hohmann G W. A rapid inversion technique for transient Electromagnetic soundings[J].Physics of the Earth and Planetary Interiors, 1989,53:384-404.

6. Macnae J. Imaging quasilayered conductive structures by simple processing of transient electromagnetic data[J]. Geophysics, 1987, 52(4):545-554.

7. Zhdanov M S,Kelller G V. The Geo-electrical Methods in Geophysical Exploration[M]. Netherlands: Elsevier Scientific Publishing House, 1994.

8. Coggon J H. Electromagnetic and electrical modeling by the finite element method[J]. Geophysics, 1971, 36(1):132155.

9. William L, Rodi. A technique for improving the accuracy of finite element solution for magnetotelluric data[J]. Geophysics, 1976,50 (7) :483-506.

10. Wannamaker P E, Stodt J A, Rijo L. A stable finite element solution for two-dimensional magnetotellnric modeling[J]. Geophysics, 1987, 88 (5):277 -296.

11. Lugao P, Wannalnaker P E. Calculating the two-dimensional magnetotelluric Jacohian in finite elements using reciprocity[J]. Geophysical Journal International, 1996, 127(2):806-810.

12. Frank A, Ralph B, Klaus S. 2D finite element modeling of plane-wave diffusive time-harmonic electromagnetic fields using adaptive unstructured grids[A]. Proceeding of the 17th Workshop,2004, S2:1-6. 
13. Constable C S, Parker R L, Constable C G. Occam's inversion: A practical algorithm for generating smooth models from electromagnetic sounding data. Geophysics, 1987,52:289 300.

14. Xu Shizhe, Liu Bin. The curve comparision method of MT inversion for one-dimensional continuous medium[J]. Chinese Journal of Geophysics. 1995(05). doi:10.1007/BF02006258.

15. Yu Nian, Hu Xiang-Yun et.al. 2017. Electrical structure of Longling area in western Yunnan and its effect on route selection of the Dali-Ruili railway. Chinese Journal of Geophysics. 60(6):2442-2445, doi:10.6038/cjg20170632.

16. Wu Xiaoping, Xu Guoming. Improvement of occam's inversion for MT data[J]. Chinese Journal of Geophysics. 41(4),1998(7).

17. Constable S C, Parker R L, Constable C G. Occam's inversion: a practical algorithm for generating smooth models from EM sounding data. Geophysics, 1987,52(1):289-300

18. Smith J T, Booker J R. Magnetltelluric inversion for minimumstructure[J]. Geophysics, 1988,53(12):1565-1576

19. Wannamaker P E, Stodt J A, Rijo L.1987.A stable finite element solution for two-dimensional magnetotellnric modeling[J]. Geophysics, 88(5):277-296.

20. GD Egbert, J R Booker. Robust estimation of geomagnetic transfer functions[J].Geophysics.1986, $87: 175 \sim 194$.

21. De Groot-Hedlin C, Constable S C.1990. Occam's inversion to generate smooth, two-dimensional models from electromagnetic sounding data [J]. Geophysics, 55:1613-1624.

22. Zhao Guoze, et.al. Investigation on $\mathrm{mt}$ data along Yanggao-Rongcheng profile by two-dimensional inversion[J]. Chinese Journal of Geophysics. 1997(01). doi: CNKI: SUN: DQWX.0.1997-01-004.

23. Yangwencai, et.al. Integrated geophysical profile from Tangchen to Lianshui[J]. Chinese Journal of Geophysics. 1999(02). doi: 10.3321/j.issn:0001-5733.1999.02.008.

24. Hu Xiangyun, etc.al. The magnetotelluric anisotropic two-dimensional simulation and case, analysis[J]. Chinese Journal of Geophysics. 2013(12). doi:10.6038/cjg20131229.

25. Jing Sheng, et.al. Ctustal electrical structure along the Hezuo-Dajing profile across the Northeastern Margin of the Tibetan Plateau [J]. Chinese Journal of Geophysics. 2012,55(12). doi:10.6038 /j. issn. 0001-5733.2012.12.010.

26. Gilda Currenti et.al. Static stress changes induced by the magmatic intrusions during the 2002-2003 etna eruption[J]. journal of geophysical research, Vol.113, B10206, doi:10.1029/2007JB005301,2008.

27. Silvio Mollo et.al. Editorial for the Special Issue "Mineral Textural and Compositional Variation as a Tool for Understanding Magmatic Processes”. Minerals 2021,11,102. https://doi.org/10.3390/min11020102.

28. Hugo K.H. Olierook et.al. Bayesian geological and geophysical data fusion for the construction and uncertainty quantification of 3D geological models[J]. Geoscience Frontiers. https://doi.org/10.1016/j.gsf.2020.04.015.

29. Hu Zhao, et.al. 2019. Application of Apparent Resistivity Ratio on the Interpretation of Small Central-loop TEM Survey in Areas of Conductive Overburden[J]. JOURNAL OF ENVIRONMENTAL AND ENGINEERING GEOPHYSICS,24(3):479- 483.

\section{Author contributions}

Li Bin and Cheng Qiang defined the overall problems and designed the study, Li Bin wrote the manuscript and prepared the figures. Cheng Qiang and Feng Chongde guided the research, reviewed the model and graphics. Yu Jianhua, Zhao Hu and Xiao Xuepei reviewed the graphics, and revised the paper. All authors provided critical discussion and approved its submission.

\section{Attach}

About the author: Li Bin, male, born in 1982, doctoral student, senior engineer, mainly engaged in production and research in engineering geophysical prospecting and engineering geology. E-mail: libin@ schdri.com

*Corresponding author: Yu Jianhua, male, born in 1976, senior engineer, mainly engaged in production and research in engineering geology and Geotechnical design. E-mail: yujianhua@schdri.com 


\section{Figures}
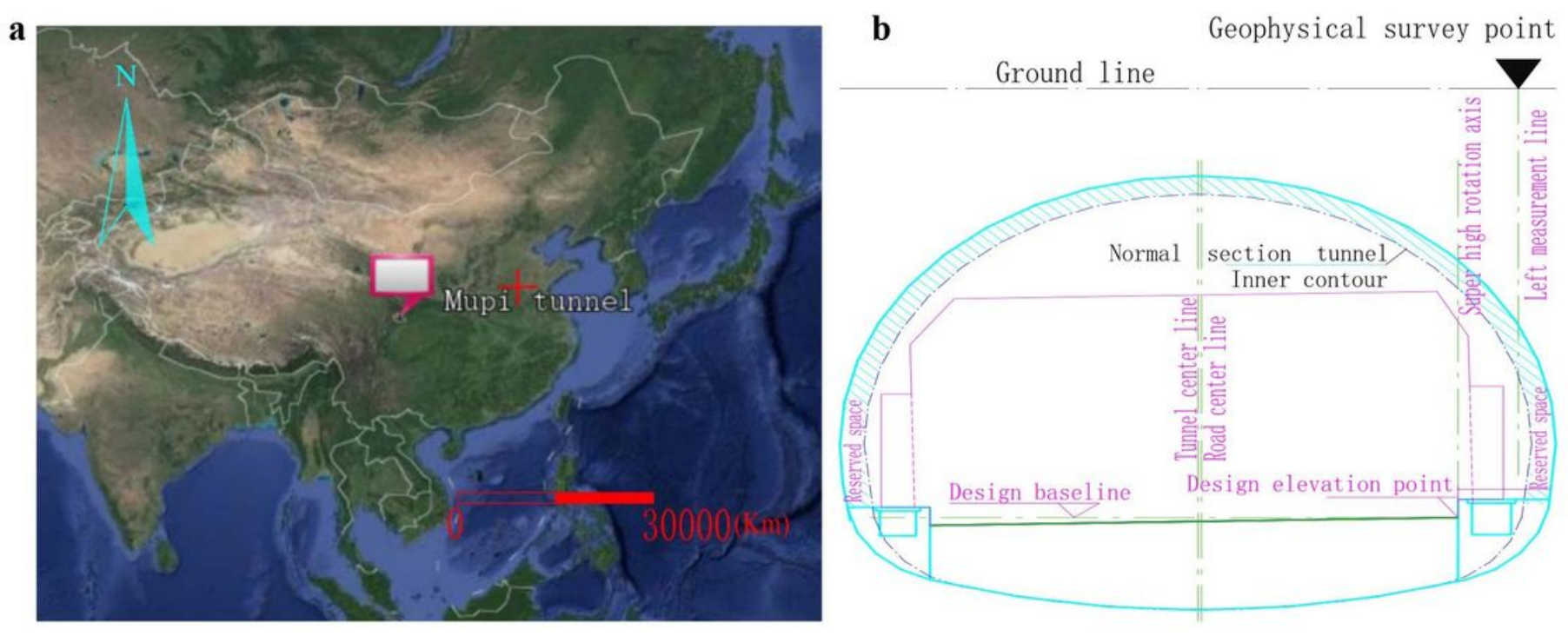

\section{Figure 1}

Location of the research area. (a) Location of the research area and geological survey. (b) Schematic diagram of Mupi tunnel design and Geophysical survey points. The map is based on Google satellite image, showing the location of the research area. The legend and other line in the map were created using AutoCAD version 2021 (https://www.autodesk.com) and CorelDRAW version 2021 (https://www.coreldraw.com). Note: The designations employed and the presentation of the material on this map do not imply the expression of any opinion whatsoever on the part of Research Square concerning the legal status of any country, territory, city or area or of its authorities, or concerning the delimitation of its frontiers or boundaries. This map has been provided by the authors. 

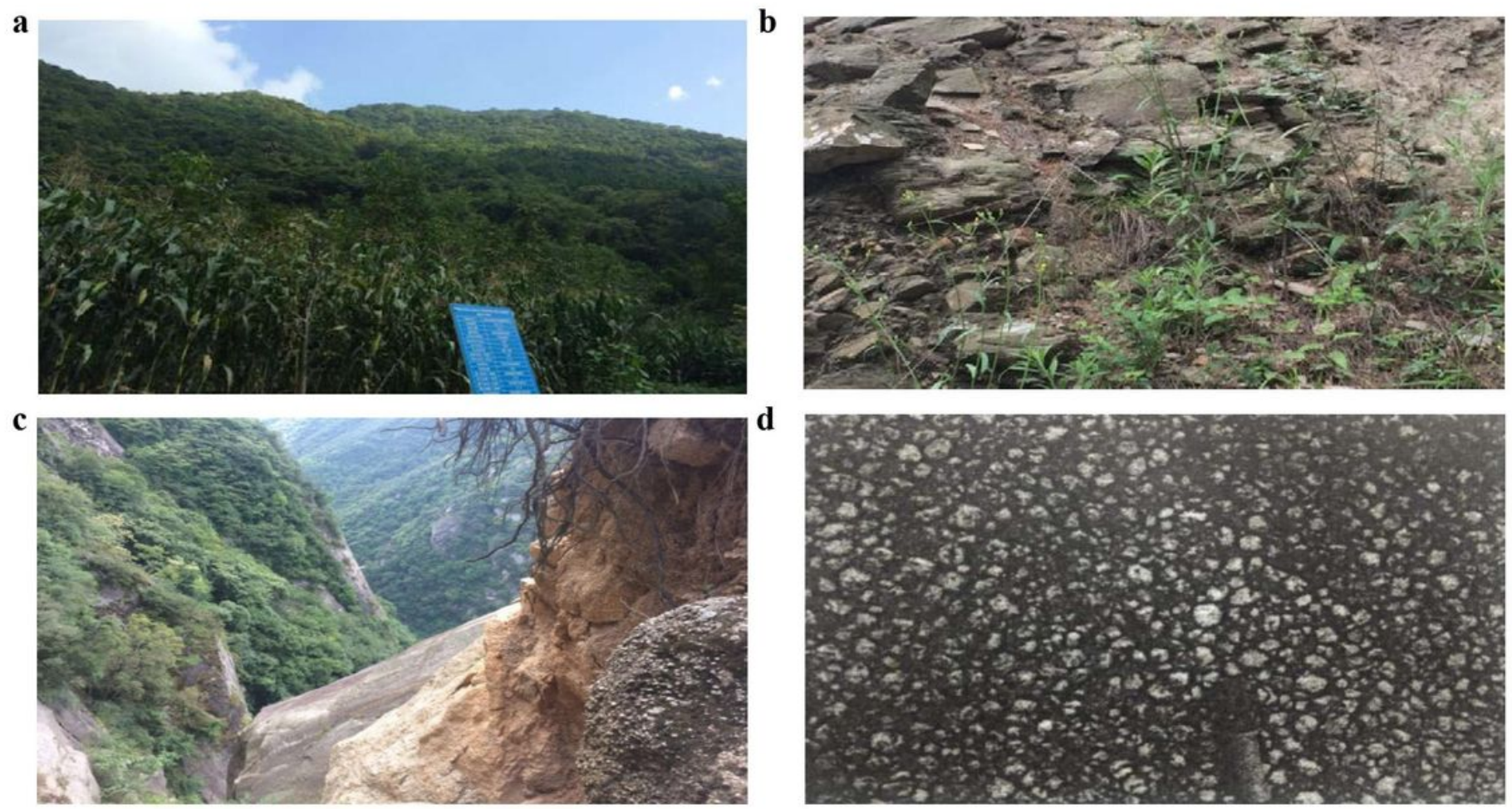

\section{Figure 2}

Topography and surface lithology photos of Mupi Tunnel. (a) Topographic photos of the entrance of the Mupi tunnel. (b) Lithology photo of the stratum at the entrance of Mupi Tunnel. (c) Lithology photo of the surface of the middle section of the Mupi Tunnel. (d) Mupishaiziyan photo. The right corner of the photo (c) is the Mupishaiziyan, and the picture (d) is taken after magnifying several times. Note: The designations employed and the presentation of the material on this map do not imply the expression of any opinion whatsoever on the part of Research Square concerning the legal status of any country, territory, city or area or of its authorities, or concerning the delimitation of its frontiers or boundaries. This map has been provided by the authors. 


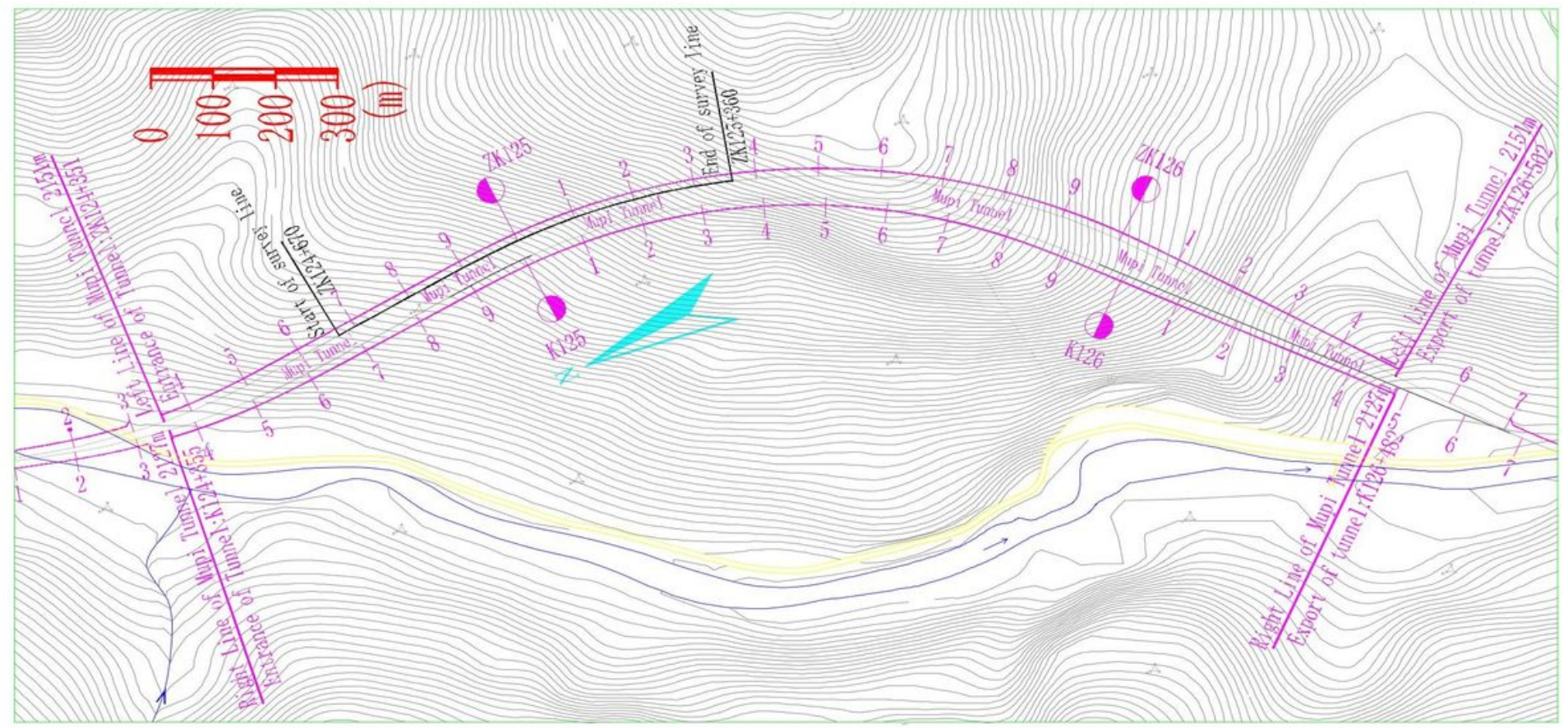

\section{Figure 3}

Layout Plan of Magnetotelluric Survey Line for Mupi Tunnel. The measurement line is arranged along the measurement line of the left hole of the Mupi Tunnel, as shown in Fig. 1b, the distance between the measurement line 159 and the center line of the tunnel is 5.25 meters.

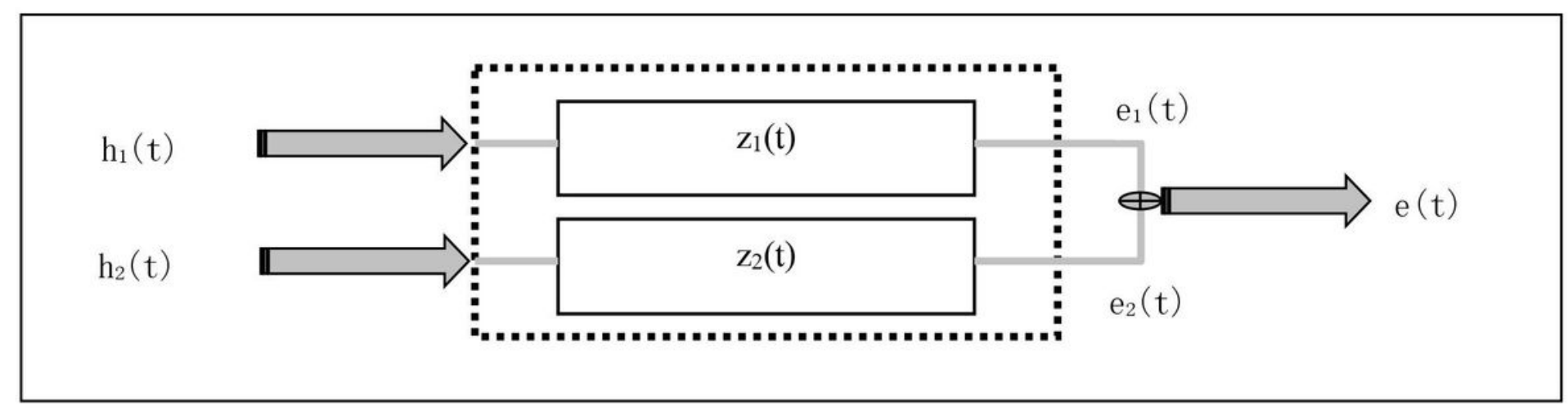

\section{Figure 4}

Mathematical Model of Magnetotelluric Method for Highway Tunnel. 


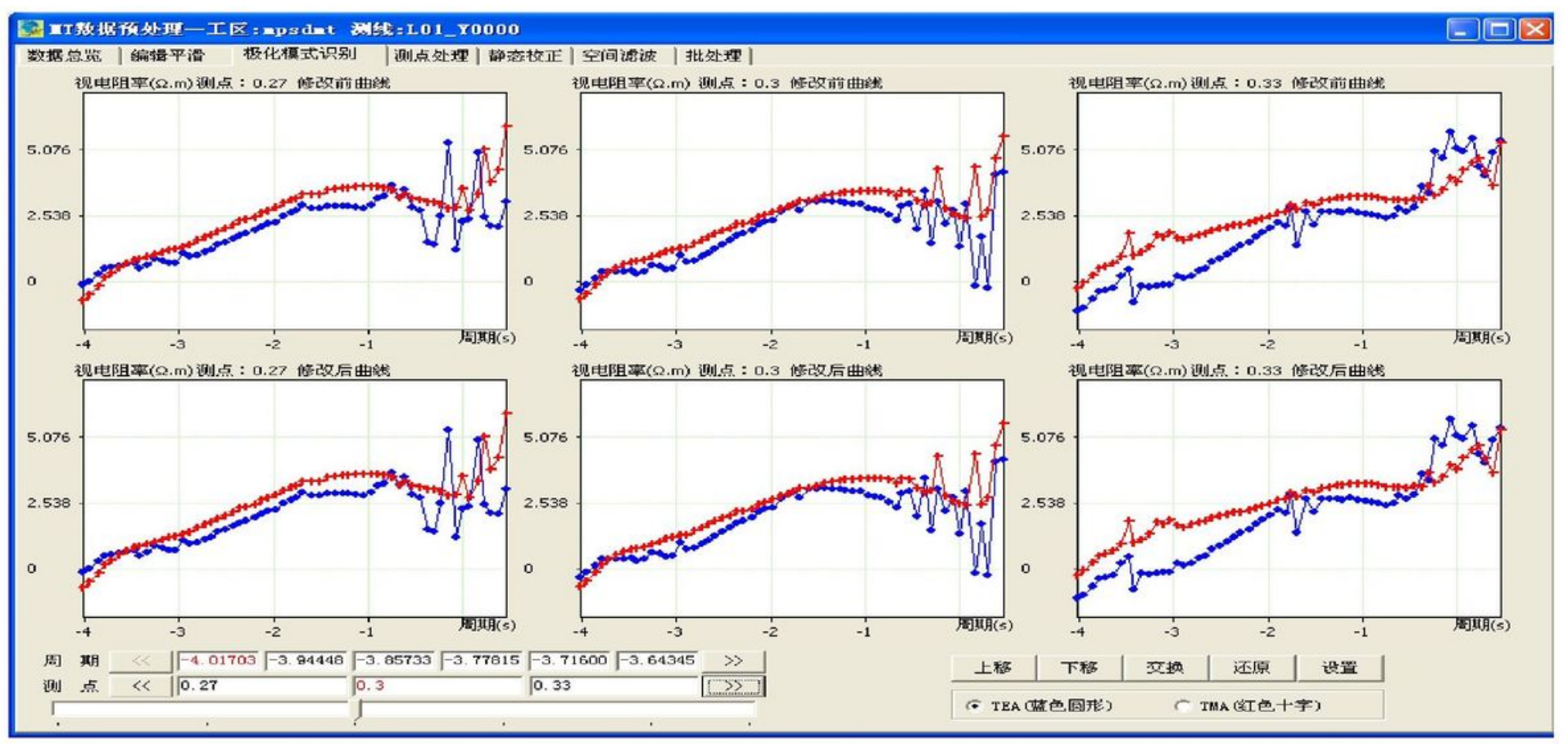

Figure 5

MT data of Mupi tunnel (TE mode apparent resistivity, section $0.27-0.33 \mathrm{~km}$, point ZK124+850,880,910).
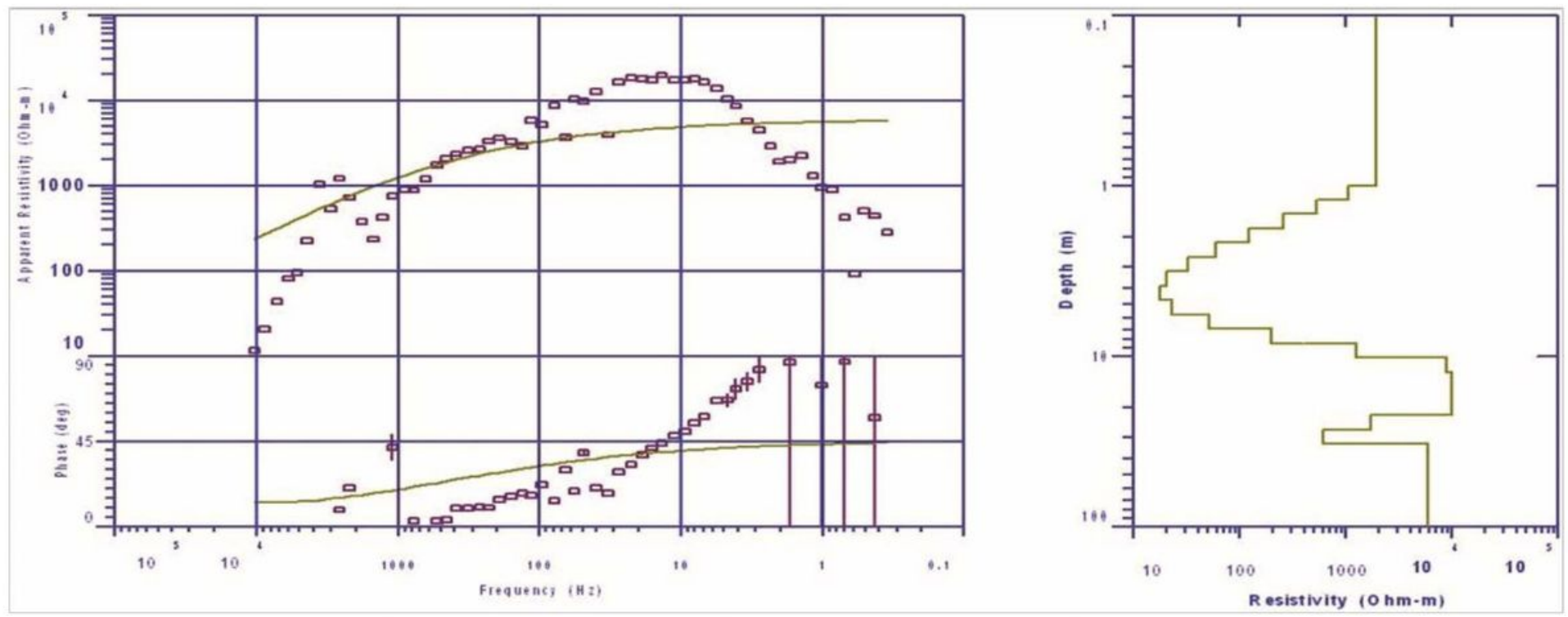

\section{Figure 6}

1D inversion map of ZK124+670 measuring points of Mupi Tunnel. 
a

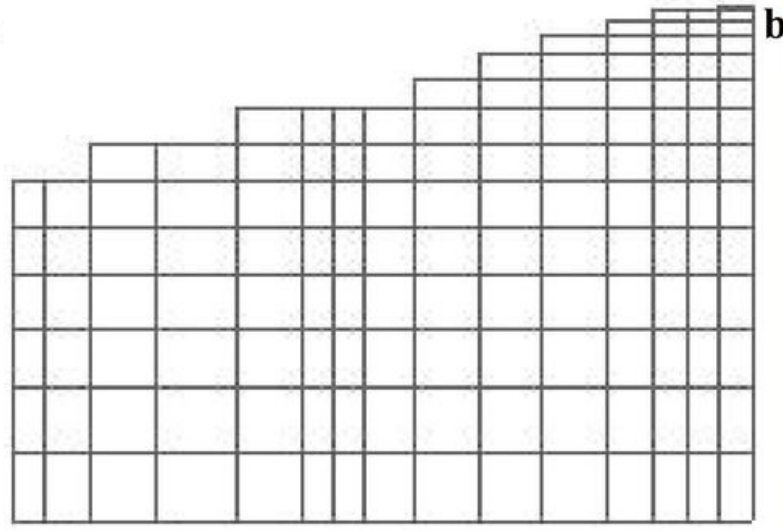

OCCANBCan

atein

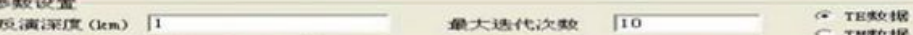

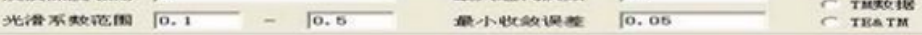

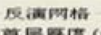

(10)

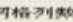

10.460645

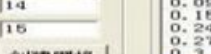
gukemat

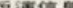

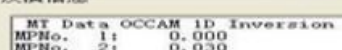

MPr.:

MPH: 1 :

MPH:

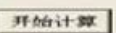

c

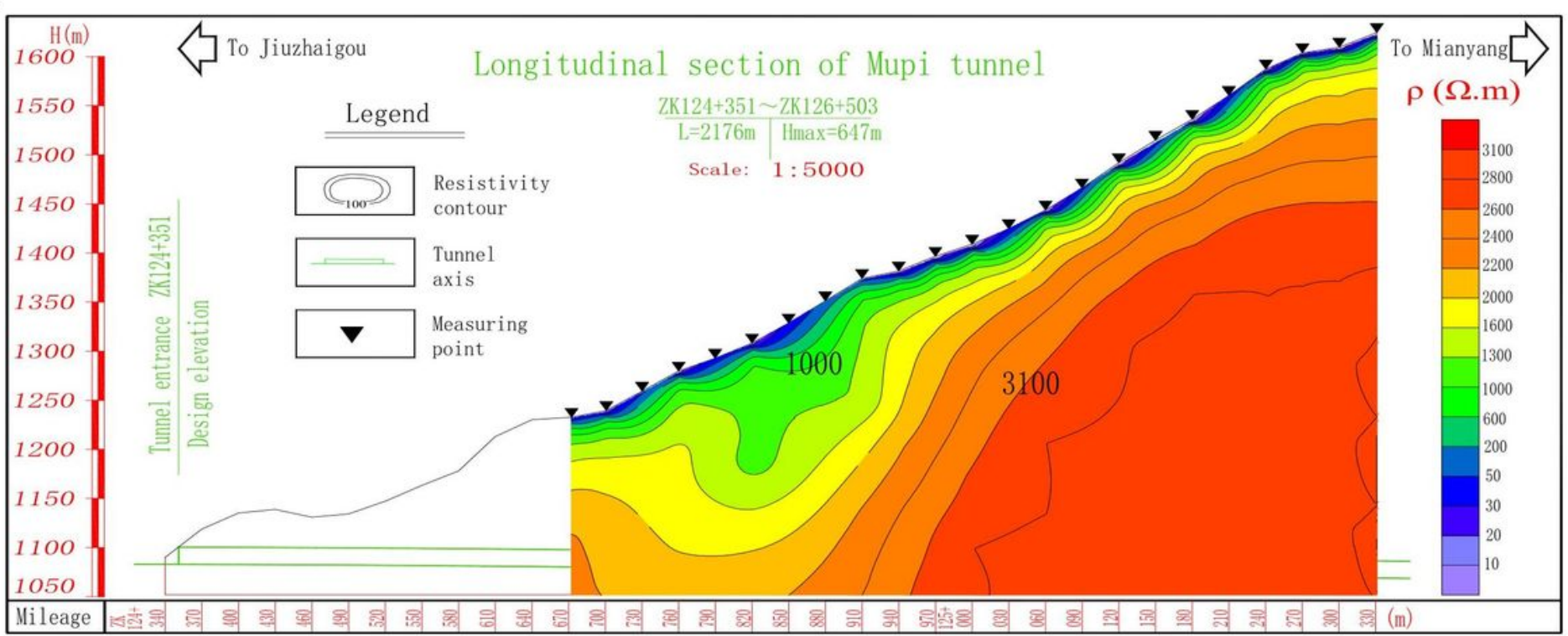

Figure 7

Mupi tunnel inversion map. (a) Occam inversion grid division (b) Occam inversion parameter selection (c) Occam inversion apparent resistivity contour map 


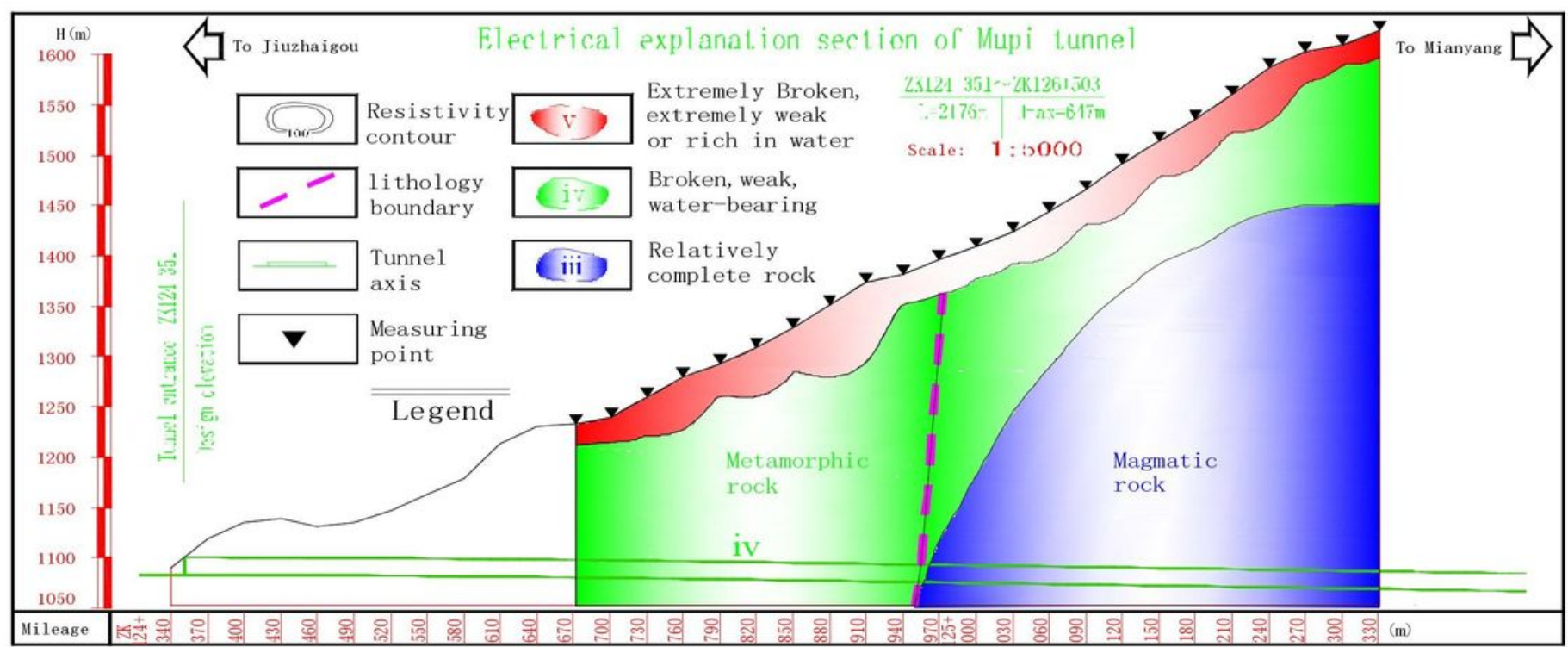

b

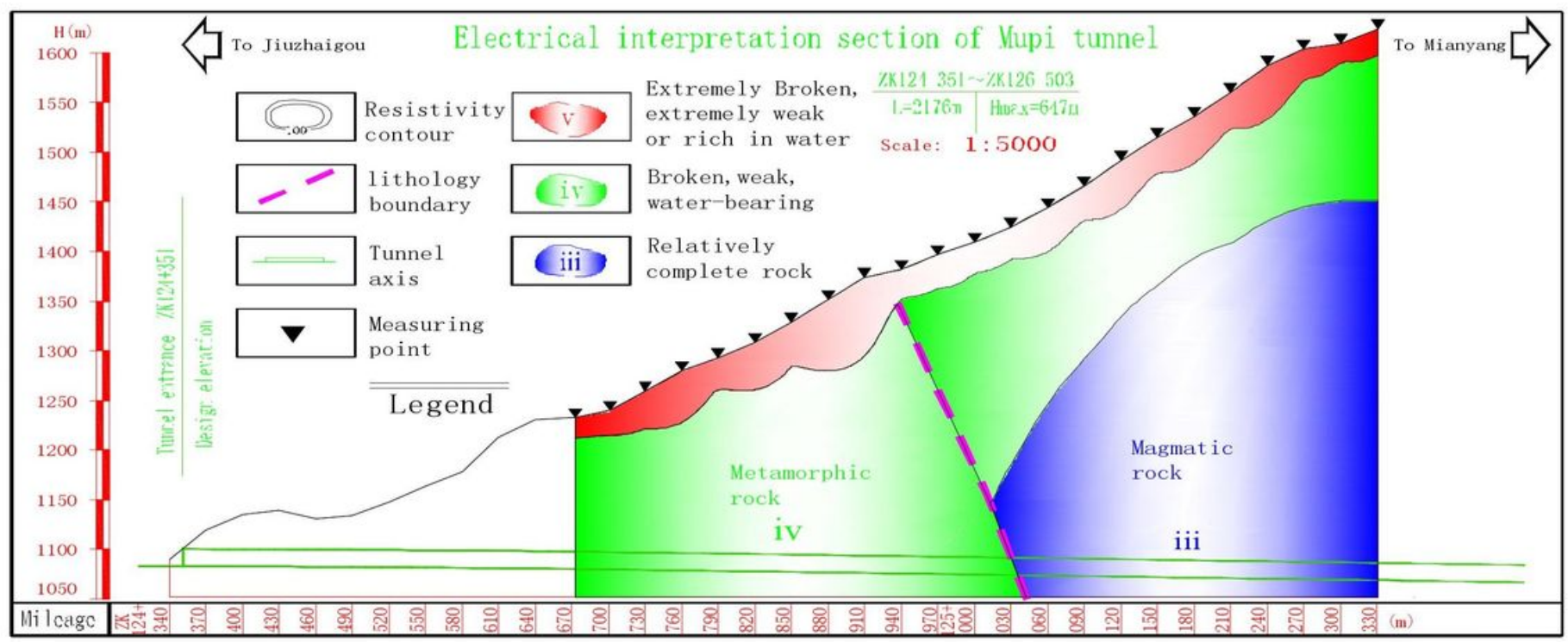

Figure 8

Mupi Tunnel Electrical Geological Interpretation Section. (a) Preliminary electrical geological interpretation profile. (b) Comprehensive geological results, considering the occurrence of metamorphic rocks and magmatic rock intrusions, modified electrical geological interpretation section. 
a

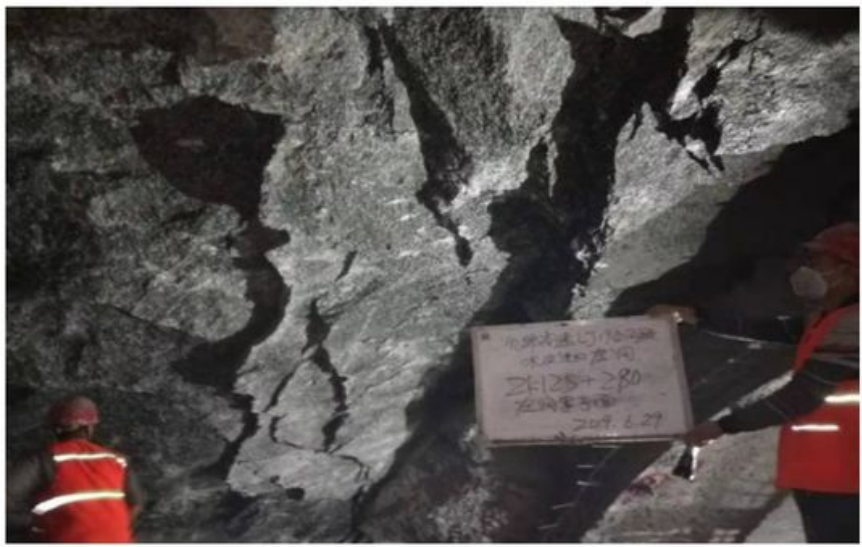

c

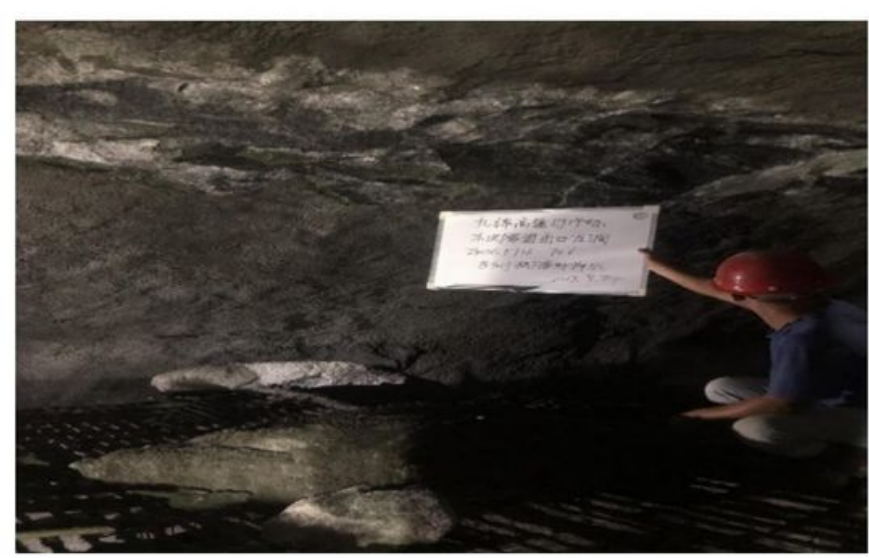

b

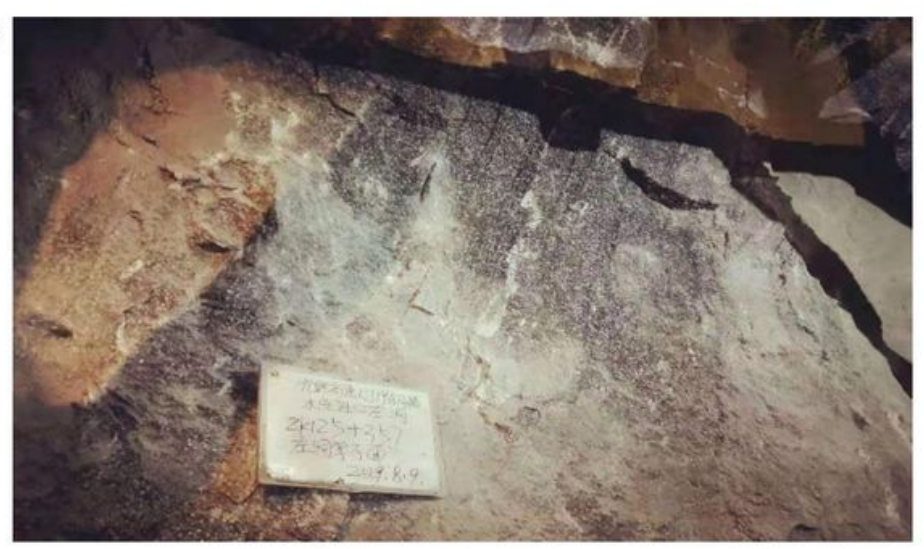

d

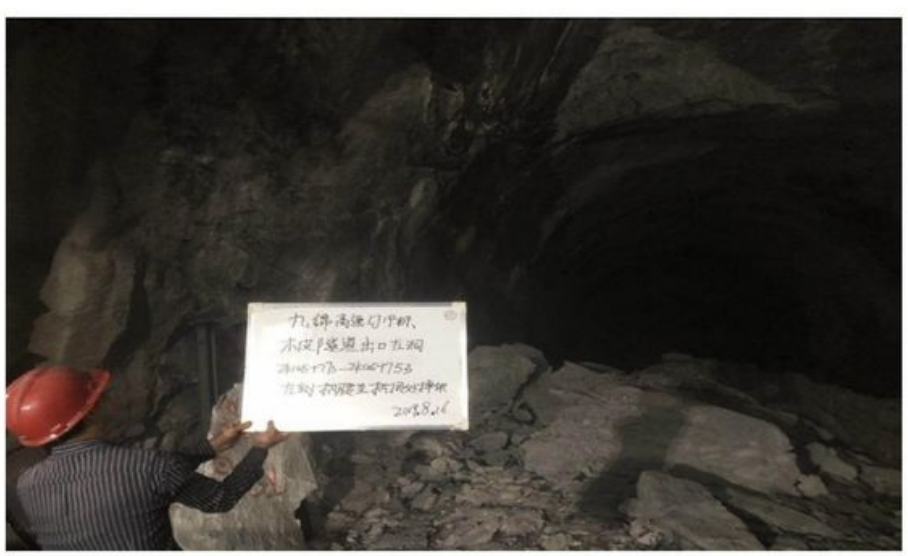

Figure 9

Mupi tunnel construction photos. (a) Mupi left hole ZK125+234 surrounding rock photos. (b) ZK125+280 tunnel face surrounding rock photos. (c) ZK125+706-716 left side arch waist surrounding rock falling photos. (d) ZK125 +773 Photos of the left arch from the waist to the top of the vault. 
a $(\mathrm{Km})$
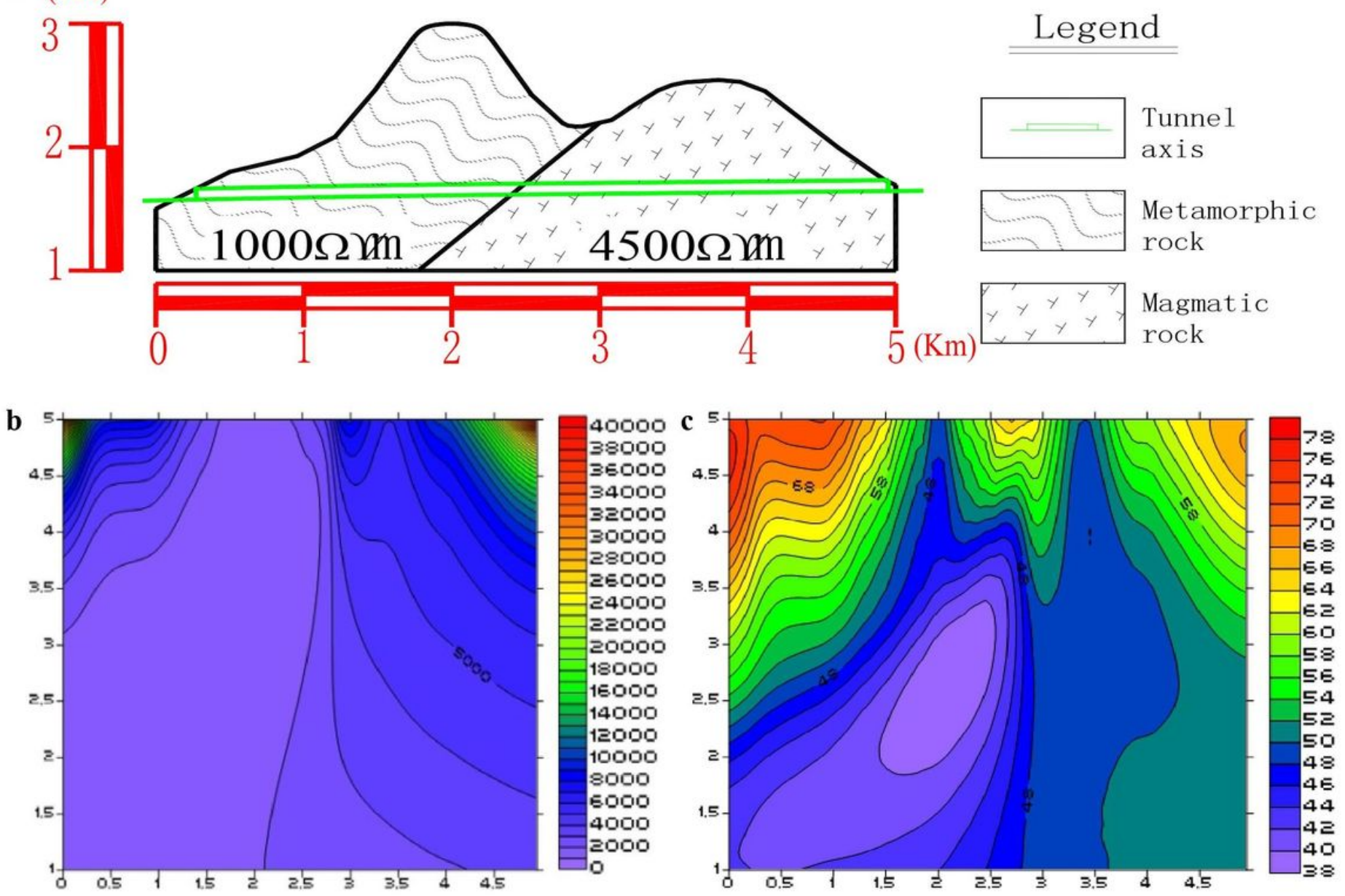

Figure 10

Magnetotelluric Forward Numerical Simulation of Mupi Tunnel. (a) Different lithology models of the undulating terrain of the tunnel. (b) TE mode apparent resistivity profile. (c) TE mode impedance phase profile. Note: The designations employed and the presentation of the material on this map do not imply the expression of any opinion whatsoever on the part of Research Square concerning the legal status of any country, territory, city or area or of its authorities, or concerning the delimitation of its frontiers or boundaries. This map has been provided by the authors. 

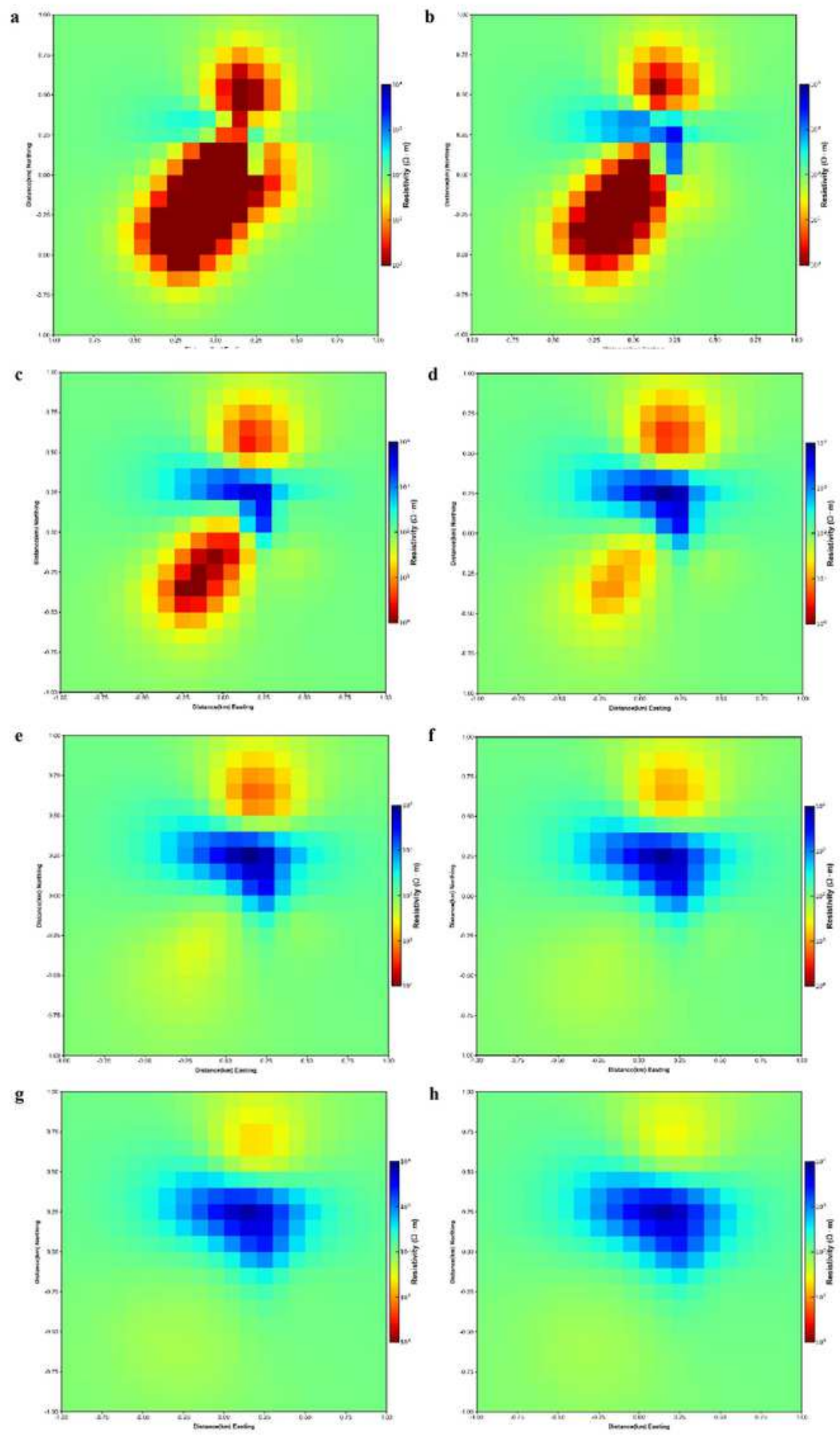

\section{Figure 11}

Three-dimensional inversion map of veneer tunnel. (a) N-E-plane-at-Depth $0 \mathrm{~km}$. (b) N-E-plane-at-Depth 1 km. (c) N-E-plane-at-Depth 2 km. (d) N-E-plane-at-Depth 3 km. (e) N-E-plane-at-Depth 4 km. (f) N-E-planeat-Depth $5 \mathrm{~km}$. (g) N-E-plane-at-Depth 6 km. (h) N-E-plane-at-Depth 7 km. Note: The designations employed and the presentation of the material on this map do not imply the expression of any opinion whatsoever on the part of Research Square concerning the legal status of any country, territory, city or 
area or of its authorities, or concerning the delimitation of its frontiers or boundaries. This map has been provided by the authors. 